\title{
Learning and International Transmission of Shocks*
}

\author{
Warwick J. McKibbin ${ }^{\dagger}$ \\ CAMA, Australian National University; \\ Lowy Institute for International Policy; \\ The Brookings Institution \\ Kang Yong Tan ${ }^{\ddagger}$ \\ University of Oxford; \\ CAMA, Australian National University
}

February 20, 2007

\begin{abstract}
This paper studies the implications of adaptive learning in the modelling of intercountry linkages in a two-region MS-GCubed (MSG3) model built on micro-founded behaviors of firms and households. The nature of the transmission process under rational expectations versus adaptive learning (Evans and Honkapohja, 2001) is explored. We investigate the propagation mechanism within and across borders for various shocks and policy changes within the United States: change in inflation target, fiscal policy, productivity shock, and rise in equity risk. Adaptive learning is found to change the short run sign of transmission in most cases but this also depends on the fraction of forward-looking agents in the economy. This suggests the choice of expectations formation scheme is crucial in large-scale macroeconomic models.
\end{abstract}

JEL classification: D83, E60, F42

Keywords: adaptive learning, transmission of shocks, large-scale macroeconomic model.

\footnotetext{
*An earlier version of this paper was presented at the Globalisation and Regionalism Conference in Sydney organised jointly by the Centre for Applied Macroeconomic Analysis of the Australian National University, the European Central Bank and the Lowy Institute for International Policy in December 2005. We thank George Evans, Bruce Preston, and David Vines for helpful suggestions and encouragement. The views in this paper do not represent that of the institutions McKibbin is associated with. All remaining errors are ours.

${ }^{\dagger}$ Correspondence: Centre for Applied Macroeconomic Analysis, Australian National University, Canberra ACT 0200, Australia. Email: wmckibbin@msgpl.com.au. URL: http://www.sensiblepolicy.com.

${ }^{\ddagger}$ Correspondence: Centre for the Study of African Economies, Department of Economics, University of Oxford, Manor Road, Oxford OX1 3UQ, UK. Email: kang.tan@economics.ox.ac.uk. URL: http://users.ox.ac.uk/ econ0206.
} 


\section{Introduction}

Expectations play a significant role in the international transmission of shocks and policy changes. The standard treatment of expectations formation remains the rational expectations (RE) paradigm. Large-scale macroeconomic models, based on coherent theoretical foundation, like the G-Cubed model of McKibbin and Wilcoxen (1998a) and the MSG2 model of McKibbin and Sachs (1991) have been popular tools for studying the impact of policies on the world economy. ${ }^{1}$ These models are formulated with RE assumption, nominal rigidities and intertemporal optimization on the part of economic agents. However the assumption of informational efficiency, under RE, has been criticized for being unrealistic. Sargent (1993) concludes that RE models impose too much knowledge on the part of agents within the model than is possessed by an econometrician.

The contribution of this paper is to revisit the expectations formation assumption imposed on agents. The paper examines the implications of learning in the analysis of inter-country linkages, that is, how shocks are transmitted within and across borders when economic agents are assumed to learn about the structural relations of the global economy. In particular, this paper explores three issues: (i) the signs and magnitude of transmission effect across borders, (ii) the volatilities and forecasting performance relative to the RE benchmark, and (iii) the robustness of the results to various parameterization in the learning algorithms. The novelty of this work is that it studies the transitional dynamics under both RE and adaptive learning in an empirically realistic two-country macroeconomic model.

To address these issues, we use a two-region MS-GCubed (MSG3) multi-country model comprising of the United States and the rest of the world (ROW). ${ }^{2}$ In this stylized model the main features of the empirical model are incorporated but the ROW is assumed to be a mirror image of the US. This is done to minimize the scale of a very large numerical problem, and is meant to provide some illustrative insights for future analysis in the larger model. The model is solved and simulated under RE to provide the benchmark results.

The concept of learning is modelled using adaptive learning (Evans and Honkapohja, 2001). Instead of endowing agents with complete information as in RE, learning agents are modelled to behave like econometricians who update time-varying parameters of the minimal state-space representation of the MSG3 model using least square estimation techniques. To study real time learning, the recursive least squares (RLS) algorithms with decreasing gain and various constant gains were used. These values were chosen based on recent applications of learning in macroeconomics by Milani (2006) and Orphanides and Williams (2002).

The timing of events in the learning model unfolds as follows. At $t-1$, agents are endowed with the current information set and beliefs about the structural relation of the

\footnotetext{
${ }^{1} \mathrm{~A}$ survey of the major large-scale multi-country models and the nature of international transmission in these models can be found in Bryant et al. (1988).

${ }^{2}$ The MSG3 model is a 2 sector version of the estimated G-cubed model aggregated to be similar in scale to the calibrated MSG2 model of McKibbin and Sachs (1991).
} 
economy at the minimal state-space level (that is, they know the structural parameters and functional form) of the model. At time $t$, a shock occurred in the US economy. Learning agents operating in the global economy update their estimates of the structural relationship of the global economy using the adaptive learning algorithm. In return, their expectations of forward-looking variables affect the time path of the economy in the next period. The nature of learning is adaptive in the sense that expectations are revised over time as new observations become available. Consequently, this model becomes self-referential in nature (Marcet and Sargent, 1989a and 1989b).

Being an empirical enquiry on the effects of learning, this paper builds on earlier works of adaptive learning in macroeconomics. These include, inter alia, Hall and Garratt (1995) and Garratt and Hall (1997). These authors have focused specifically on the formation of exchange rate expectations as a learning process. However, their analysis has not considered the role of other forward-looking variables. This paper extends recent contribution by Milani (2006) and Williams (2003). Milani has applied "irrational expectations" econometric technique and use the estimated parameters to perform simulations under learning for a closed version of the US economy. Williams has studied the implications of learning on the persistence and volatilities of simple monetary and real business cycle models. This paper extends Williams by introducing learning into a two-country macroeconomic model. This paper is closely related to Milani (2006) who examines the relevance of "mechanical" source of rigidities in explaining actual time series data. Although our approach uses a model that is partly estimated and partly calibrated, we are able to explore the nexus between nominal rigidities and learning by varying a key parameter in the MSG3 model.

Using adaptive learning algorithms, this paper places some empirical magnitudes on the size of policy spillover among countries under learning. To do so, four types of independent shocks and policy changes that are common in large-scale macroeconomic modelling analysis were considered. These are changes in monetary policy (inflation target shock), fiscal policy, productivity shock and a change in the equity risk premium. These shocks are assumed to be persistent and decay exponentially with a factor of 0.5. The initial values of these shocks in the first year of simulations are based on the standard deviations of the US annual data between 1960 to 2002.

The choice of these policy changes and shock scenarios warrants some justification. Inflation targeting has increasingly become a common framework for the implementation of monetary policy. Thus, it would be interesting to evaluate its transmission effect within and outside the US. ${ }^{3}$ Changes in fiscal positions, especially amongst the industrial countries, could affect the nature of international transmission effects and the real exchange rate in the medium term (see for example, Frenkel and Razin, 1986; Bianconi and Turnovsky, 1997). The simulated data obtained under the productivity shock could be used for analysis on outstanding puzzles in the international RBC literature. A change

\footnotetext{
${ }^{3}$ Inflation targeting is increasingly adopted by several central banks. These include Australia, Canada, New Zealand, the United Kingdom and the United States. See Rudebusch and Walsh (1998) for an assessment on the advantages and disadvantages of inflation targeting in the US.
} 
in the equity risk premium is an important source of fluctuations in events like the Asian Financial Crisis and the consensus view of a slowdown of the global economy in 2002 (see McKibbin, 1998; McKibbin and Vines, 2000 and 2003).

Using the MSG solution algorithm, we simulate for the benchmark RE result. To incorporate the concept of adaptive learning, we augment the MSG solution algorithm to compute expectational stability (E-stability) conditions and real-time learning via the RLS and constant gain learning algorithms. By satisfying the E-stability conditions, agents learn the true values of time-varying parameters and converge to the rational expectations equilibrium (REE) asymptotically with positive probability at the limit (Evans and Honkapohja, 2001). The effects of learning on short run policy responses are obtained by the RLS algorithm and constant gain algorithms with fixed constant gains of 0.03 and 0.10. It is well known in the recursive identification literature that a constant gain learning algorithm will lead to convergence towards an ergodic steady state distribution of the REE.

We find that, under adaptive learning, the transitional dynamics are significantly different from those predicted by RE. The key findings in this paper may be summarized as follows. First, in the standard learning case, the short run transmission effects of shocks and policy changes differ significantly from the predictions of the MSG3 model under RE. Amongst the shocks considered, these transmission effects actually have the opposite signs initially, except for changes in the monetary/inflation target in the short run. This result is robust across the gain sequences considered in the analysis. These signs nonetheless revert to the standard RE predictions of the MSG3 model over time since E-stability conditions are satisfied. Second, in contrast to findings in Williams (2003), learning has led to significant deviations in the transition dynamics under various shock scenarios and this finding is robust across learning algorithms. This is because many variables depend on forward-looking variables in the MSG3 model: real exchange rate, Tobin's $q$, long term real interest rates, human wealth and price levels. These variables are affected directly by time-varying expectations under learning. The greater variances uncovered in these variables suggest agents learn about the structural relationship of the model slowly, albeit the use of constant gain adaptive learning algorithms which enhances the alertness of learning agents. Finally, by increasing the fraction of forward-looking agents in the MSG3 model with learning, we find that the opposite signs of transmission uncovered in the standard learning case changed except for equity risk.

The rest of the paper is structured as follows. Section 2 describes a stylized twocountry MSG3 model. Section 3 explains how the model is solved under RE and adaptive learning. Section 4 examines and discusses the effects of learning in the international transmission of shocks by comparing the dynamic responses of the world economy under $\mathrm{RE}$ and learning. Section 5 present some summary statistics to evaluate the performance of various learning algorithms. Section 6 conducts sensitivity analysis on the learning algorithms, and Section 7 concludes. Appendix A details the structure of the MSG3 model and Appendix B provides a summary of equilibrium conditions. These can be 
found at the back of the paper.

\section{Theoretical Framework of MSG3 Model}

The MSG3 model is based on theoretical underpinnings of the dynamic stochastic general equilibrium (DSGE) approach. It is a large-scale numerical model designed to study a variety of policy changes and shocks within and across countries. This model also incorporates features of traditional computational general equilibrium (CGE) models, Real Business Cycle (RBC) models and Keynesian macroeconometric models.

The predecessor of the MSG3 model is the MSG2 model, a single sector dynamic intertemporal general equilibrium (see McKibbin and Sachs, 1991). The MSG G-cubed (hereafter, G-cubed) model in McKibbin and Wilcoxen (1999) is a multi-country multisector dynamic intertemporal general equilibrium model. The MSG3 model is based on a sectoral aggregation from twelve to two sectors of the G-cubed model. The level of aggregation is of a similar degree to the MSG2 model.

As the MSG3 model is an aggregated version of the G-cubed model, discussion of the MSG3 model will follow closely to that of the G-cubed model. The key parameters of the G-cubed model, such as the elasticities of substitution in consumption and production, are estimated econometrically following the approach undertaken for the disaggregated, econometrically estimated, intertemporal general equilibrium model of the US economy in Jorgenson and Wilcoxen (1990). To do so, a consistent time series of input-output tables were first constructed for the US. ${ }^{4}$ Next, the standard industrial classifications were converted and aggregated to twelve sectors. ${ }^{5}$ To capture the dynamics of real data, several assumptions were made to generate a baseline solution. First, the sum of the long run rates of population and productivity growth of the world is assumed to be $2.5 \%$ per annum. Also, the long run real interest rate is assumed to be $5 \%$ per annum. Second, tax rates and government expenditure allocated to each sector remain the same as in the base year of 2002. Third, constant terms are added to each of the equations for the costate variables in the model so that their values correspond to that of the historical data.

The main features making the MSG3 model attractive for policy analysis are as follows. First, in the long run the world economy is on the balanced growth path of a neoclassical Solow/Swan/Ramsey growth model. The MSG3 model is based on explicit intertemporal optimization of agents (consumers and firms) in each economy subject to explicit intertemporal budget constraints. This follows Sargent (1987), Blanchard and Fischer (1989), and Obstfeld and Rogoff (1996). In the short run, the dynamics of the model

\footnotetext{
${ }^{4}$ This is based on a series of US input-output transactions tables produced by the Bureau of Economic Analysis (BEA) for the years 1958, 1963, 1967, 1972, 1977 and 1982. More details can be found in McKibbin and Wilcoxen (1994).

${ }^{5}$ The dataset was adjusted in the following ways (see McKibbin and Wilcoxen, 1999). First, consumer durables are classified as investment in the G-cubed model. These are classified as consumption items in the US National Income and Product Accounts and the input-output tables. Second, the value added of each sector was supplemented from a dataset on capital and labor input. Third, prices for each good are collected from the output and employment dataset available from the Bureau of Labor Statistics (BLS).
} 
are driven by Keynesian style nominal rigidities in goods and labour markets. Households and firms maximize intertemporal utility and profit functions subjected to intertemporal budget constraints. ${ }^{6}$ In order to track the characteristic of macroeconomic time series better, the behavior of agents (consumers and firms) has been adjusted to allow for short run deviations from the intertemporal optimized condition. This arises due to either myopia or constraints on households and firms to borrow at the risk free rate of the government bond. Such deviations take the form of rules-of-thumb and are consistent with an optimizing agent not updating future expectations based on the current information set. Also, these rules-of-thumb are chosen so as to generate the same steady state behavior as the optimizing agents. The weight allocated to rule-of-thumb is 0.7. Short run nominal wage rigidities exist in the model. Due to different institutional arrangements, the degree of rigidities vary across countries. As a result, prolonged period of unemployment is a standard feature of the model. Since the model used in this paper is symmetrical by construction, the degree of rigidities are the same.

The other key feature of the MSG3 model is the explicit treatment of stock and flows. Investment leads to capital accumulation. Fiscal deficits lead to accumulation of government debt, and current account deficits lead to rising foreign claims against domestic production. The imposition of intertemporal budget constraints means that all outstanding stocks of assets will be serviced. The other more important feature of the MSG3 model is the nature of asset markets. Asset prices are determined by a combination of intertemporal arbitrage condition and RE. While real assets are imperfect substitutes, financial assets are perfect substitutes (adjusted by exogenous risk premia) and flow freely within and across the economies.

The economic interdependencies within and across countries are solved out using the MSG (McKibbin, 1987) solution algorithm coded in GAUSS. It is also important to note that the terminology of 'general equilibrium' in this context refers to the aim of capturing as much interaction as possible within the model, and is not related to the assumption of a full market clearing condition in the traditional sense. Complete documentation of the MSG3 model, including theoretical derivations, can be found in Appendix A. Appendix B details a list of key equilibrium conditions.

\section{Rational Expectations and Adaptive Learning}

There are several ways to solve the model under RE. Blanchard and Kahn (1980), and McCallum (1983 and 1998) are common techniques which allow for derivation of closed form analytical solutions. These two techniques are often used to obtain the REE solution in the adaptive learning literature. However, these solution techniques may be appropriate for univariate model or multivariate model with small dimension where analytical solutions could be easily obtained. In large-scale multi-country models, solving for the REE

\footnotetext{
${ }^{6}$ Money is explicitly introduced into the model under a constraint whereby households are required to hold money to purchase goods and services.
} 
solution could become cumbersome and computationally intensive when one considers disaggregation of goods in different markets and different forward-looking variables in asset prices, consumption and investment. Hence, the model is solved using the MSG solution algorithm.

Since the MSG solution technique is well documented (McKibbin, 1987; McKibbin and Sachs, 1991), the discussion here is heuristic. We first classify variables into various categories: lead state $\left(X_{t+1}\right)$, state $\left(X_{t}\right)$, jumping $\left(e_{t}\right)$, endogenous $\left(Z_{t}\right)$, expected state $\left(E_{t} X_{t+1}\right)$, expected jumping $\left(E_{t} e_{t+1}\right)$ and exogenous variables $\left(w_{t}\right)$. Next, the endogenous variables are substituted out by expressing them as a function of other variables in the system. After log-linearising around the initial conditions, this forward-looking model with lagged endogenous variables can be expressed as a linear expectational difference equations system:

$$
Y_{t}=\alpha+\beta E_{t} Y_{t+1}+\delta Y_{t-1}+\kappa w_{t},
$$

where $Y_{t}$ is a vector of evolving variables (comprising of $X_{t+1}$, a column vector of state variables and $e_{t}$, a column vector of jumping variables) and $w_{t}$ is a vector of exogenous variables. To attain a canonical representation, relating to its deep structural parameter matrices, the model is re-written as:

$$
\begin{aligned}
{\left[\begin{array}{c}
X_{t+1} \\
e_{t}
\end{array}\right]=} & {\left[\begin{array}{cc}
A A+B B \cdot D D 1 & 0 \\
D D 1 & 0
\end{array}\right]\left[\begin{array}{c}
X_{t} \\
e_{t-1}
\end{array}\right] } \\
+\left[\begin{array}{cc}
W D+B B \cdot W E 1 & B B \cdot F F 1 \\
W E 1 & F F 1
\end{array}\right]\left[\begin{array}{c}
E_{t} X_{t+1} \\
E_{t} e_{t+1}
\end{array}\right] & +\left[\begin{array}{c}
Z A+B B \cdot W W 1 \\
W W 1
\end{array}\right] w_{t} .
\end{aligned}
$$

Since RE is assumed, agents make use of all available information when forming expectations about future variables. To solve as a finite horizon optimization problem, we assume that the last period is $T=280$. Thus, we write the terminal condition for the jumping variable as $e_{T}=H_{1 T} X_{T}+H_{2 T} w_{t}$. Consequently, in any period we need to find the matrices which link the jumping variable to the state and exogenous variables. The rule $e_{t}=H_{1} X_{t}+H_{2} w_{t}$ governs the stable manifold property of the system. This is obtained by backward recursive iteration until $H_{1 T}$ and $H_{2 T}$ are independent of the terminal condition. After substituting this rule into (2), the model can be expressed as a linear difference equation system in terms of state and exogenous variables:

$$
\left[\begin{array}{c}
X_{t+1} \\
e_{t}
\end{array}\right]=\left[\begin{array}{c}
A_{1} \\
H_{1}
\end{array}\right]\left[\begin{array}{c}
X_{t} \\
e_{t-1}
\end{array}\right]+\left[\begin{array}{l}
A_{2} \\
H_{2}
\end{array}\right] w_{t}
$$

The stability of the system is determined by the coefficient matrix of the evolving variables. The necessary condition for stability is that the eigenvalues of this matrix has to be within unit circle. As discussed in McKibbin (1987), this method is numerically equivalent to the Blanchard-Kahn solution technique. Equation (3) can also be interpreted 
as the MSV solution expressed in vector autoregressive (VAR) form. With reference to Evans and Honkapohja (2001), this solution becomes the specification to motivate adaptive VAR learning.

To relax the RE assumption, we introduce adaptive learning following Evans and Honkapohja (2001) into the MSG3 model. Being a specific form of bounded rationality (Sargent, 1993), this framework determines if agents are able to learn about the timevarying parameters which govern the dynamics of the system (that is, learning how to form REE over time) after an observable exogenous shock has been introduced. The true data generating process of the economy is determined by the actual law of motion (ALM). However in a learning environment, agents form expectations in a non-rational manner. Using forecast rules, agents revise their forecast of forward-looking variable as more information becomes available over time. As such, in each period, the economy attains a temporary equilibrium. In return, this temporary equilibrium provides new data points for the agent's forecast rule in the next period. If suitable stability conditions are fulfilled, this sequence of parameters updating will lead to a fixed point which corresponds to the REE outcome asymptotically.

Since we are analyzing the impact of shocks on the economy in terms of deviations from the baseline, we set $\alpha=0$. Thus, (2) becomes

$$
Y_{t}=\beta E_{t} Y_{t+1}+\delta Y_{t-1}+\kappa w_{t}
$$

where $Y$ is a column vector of state and jumping variables, and $w_{t}$ a vector of exogenous variables in the MSG3 model. Corresponding to (3), the MSV solution, i.e. the perceived law of motion, takes the form

$$
Y_{t}=b Y_{t-1}+c w_{t}
$$

where $b$ and $c$ are conformable matrices. The corresponding expectations are

$$
\begin{aligned}
\widehat{E}_{t} Y_{t+1} & =\widehat{b} Y_{t}+\widehat{c} w_{t+1} \\
& =\widehat{b} Y_{t}+\widehat{c} \rho w_{t},
\end{aligned}
$$

where $\widehat{E}_{t}$ denotes expectations being formed in non-rational manner. Substituting (6) into (4) gives the ALM

$$
\begin{aligned}
Y_{t} & =\beta \widehat{b} Y_{t}+\beta \widehat{c} w_{t}+\delta Y_{t-1}+\kappa w_{t} \\
(I-\beta \widehat{b}) Y_{t} & =\delta Y_{t-1}+(\beta \widehat{c} \rho+\kappa) w_{t} \\
Y_{t} & =(I-\beta \widehat{b})^{-1}\left[\delta Y_{t-1}+(\beta \widehat{c} \rho+\kappa) w_{t}\right]
\end{aligned}
$$

From (7), the time path of $Y_{t}$ depends non-linearly on the recent $t$-period estimates of the structural parameters.

The asymptotic properties of the MSV solution under learning is determined by the 
E-stability condition. Using the PLM in (5), we obtain a mapping to the ALM in (7):

$$
T(b, c)=\left[(I-\beta b)^{-1} \delta,(I-\beta b)^{-1}(\beta c \rho+\kappa)\right]
$$

In the limit, the $T$-mapping to the fixed point of $(b, c)$ is the REE solution.

From the E-stability principle, the stability of the system under learning is determined by the matrix differential equation

$$
\frac{d}{d \tau}(b, c)=T(b, c)-(b, c)
$$

where $\tau$ is notional time. The REE under learning is E-stable if (9) is locally stable in the neighborhood of REE, that is, $(\bar{b}, \bar{c})$. From $(3)$, the REE is

$$
\bar{b}=\left[\begin{array}{l}
A_{1} \\
H_{1}
\end{array}\right]=\phi_{1}^{R E} \text { and } \bar{c}=\left[\begin{array}{l}
A_{2} \\
H_{2}
\end{array}\right]=\phi_{2}^{R E}
$$

The condition for local stability is determined by the eigenvalues of the respective Jacobian matrices of $D T_{b}(\bar{b})$ and $D T_{c}(\bar{b}, \bar{c})$. As shown in Evans and Honkapohja (2001), the REE is locally stable if the real parts of all eigenvalues associated with these Jacobian matrices are less than one. This ensures that, as more information becomes available, agents will learn to form $\mathrm{RE}$ with a large probability.

Being a multivariate model, the form of learning falls under the category of VAR learning. The timing of event behind real-time learning takes place as follows. At period $t-1$, agents are endowed with beliefs $\phi_{t-1}=\left[b_{t-1}^{\prime}, c_{t-1}^{\prime}\right]$ and the correct structure of the global economy. As discussed in Evans and Honkapohja (1998), this has to be near to the REE, $\bar{\phi}=\left[\bar{b}^{\prime}, \bar{c}^{\prime}\right]$ to satisfy stability conditions. At period $t$, the US economy is subjected to an exogenous observable shock. Using the VAR solution, they learn about the structural relation of the global economy by updating $\phi_{t}$ which subsequently affects the underlying structural dynamics of the model. This process is repeated as time elapses.

When agents are learning in real-time, the parameters $\phi_{t}=\left(b_{t}^{\prime}, c_{t}^{\prime}\right)$ are updated by the recursive least squares (RLS) algorithm:

$$
\begin{gathered}
\phi_{t}=\phi_{t-1}+g_{t} R_{t}^{-1} z_{t-1}\left(Y_{t}-\phi_{t-1}^{\prime} z_{t-1}\right) \\
R_{t}=R_{t-1}+g_{t}\left(z_{t-1} z_{t-1}^{\prime}-R_{t-1}\right),
\end{gathered}
$$

where $\phi_{t}=\left[b_{t}^{\prime}, c_{t}^{\prime}\right], z_{t-1}=\left[Y_{t-1}^{\prime}, w_{t}^{\prime}\right]$ and $g_{t}$ is the gain sequence. From (10) and (11), it is evident that the RLS algorithm is sensitive to the initial values of the coefficient matrix $\phi_{0}$ and the regressors $z_{0}$, and the choice of the gain sequence $g_{t}$. Though such choices could be made on an ad hoc basis, this may lead to different learning dynamics and often divergent time paths (Grandmont and Laroque, 1991). Thus it is key to keep the RLS within close proximity to the REE to maintain local stability properties (Evans 
and Honkapohja, 1998).

With regard to the choice of initial conditions $\phi_{0}$ and $R_{0}$, these effects should disappear over time since the asymptotic properties of the RLS algorithm are well-behaved by satisfying the E-stability condition. Carceles-Poveda and Giannitsarou (2006) highlight the importance of initial conditions in the RLS algorithm within a broad class of dynamic stochastic macroeconomic models. Considering between initial conditions chosen on ad hoc basis and randomly generated data, they found significance difference between learning dynamics and the REE outcome.

We introduce white noise shocks with arbitrarily small variances to each exogenous variables in the model. There are two motivations. First, this relates to the econometric intuition behind recursive least squares algorithm. Aymptotically, as the variables converge to the REE, $Y_{t}$ will converge to a constant, and consequently $z_{t}$ will have problems of perfect multicollinearity. The presence of white noise with small supports will break the multicollinearity problem. Second, this makes it more natural to initialize learning (and in particular, $\left.R_{0}\right)$ at the stochastic process followed by the REE.

The common gain sequences in the RLS algorithms are decreasing gain $\frac{1}{t}$ and fixed gain $\bar{g}$. The decreasing gain (or infinite memory learning) is used to derive the E-stability conditions (Evans and Honkapohja, 2001). Under infinite memory learning, agents forget observations from the distant past during the learning process as $t \longrightarrow \infty$. The decreasing gain could also be represented as $\frac{1}{t+t_{0}}$ where $t_{0}$ is the training period for the learners (Carceles-Poveda and Giannitsarou, 2006; Williams, 2003). In doing so, this effectively lowers the variability of $\phi_{t}$ and keeps it within boundary of the limit point. To do so, we set $t_{0}=100$.

Under constant gain learning, agents are alert to potential structural changes in the economy. When $\bar{g}>0$, more weight will be allocated to recent observations and subsequently lead to a faster speed of adjustment in the learning coefficient $\phi_{t}$. The system would not converge perfectly to the REE but instead towards some ergodic steady state distribution. Theoretically, $0<\bar{g} \leq 1$. As $\bar{g} \rightarrow 0$, the coefficient remains the same throughout the simulation without any form of learning. When $\bar{g}=1$, this reflects that agents are fully alert to changes in the economy and $\phi_{t}$ will converge to REE almost instantaneously. However, under such circumstances, elements in $z_{t}$ might contain identical rows or columns, and result in multicollinearity problems. As a result, the second moment matrix $R_{t}$ ceases to be invertible, and learning ceases instantaneously.

Besides acting as a tracing device, the choice of gain sequence will also affect the variability of the RLS estimates and the ALM. In Orphanides and Williams (2002), and Williams (2003), the calibrated value of $\bar{g}$ falls between the range of 0.01 to 0.10 . In what follows, we set constant gains taking values of 0.03 and 0.10 . 


\section{Numerical Results on International Transmission of Shocks}

For each shock scenario, the exogenous shock or policy variable is perturbed by one standard deviation computed based on the historical distribution of the variable. These shocks are assumed to be persistent and decay exponentially by a factor of 0.5 .

To investigate the effects of an increment in the inflation target, the standard deviation of the US CPI inflation rate between 1961 to 2002 was computed. An increase in the US government consumption to GDP ratio was modelled as a demand shock. The supply shock takes the form of a rise in the productivity of the energy and non-energy sectors in the MSG3 model. The real equity risk premium was constructed using annual data from 1960 to 2002 . The difference between real stock index returns and real risk free rate is the equity risk premium. The yield of the US three months T-bills rate is assumed to be the risk free rate.

The definition of policy or shock transmission is as follows. The effect of transmission is analyzed by the impact of policy changes and shocks on the real GDP of the US and ROW. A shock is positively transmitted when it has the same effect on both countries' real GDP. The shock is defined to be negatively transmitted when it has an opposite effect on real GDP.

The results for each shock scenario on the US and the ROW from 2005 to 2025 are contained in Figures (1) through (4). The top panel of variables is for the US while the bottom one for the ROW. Within each panel, there are six graphs exhibiting the dynamic responses of key macroeconomic variables. Within each graph, there are four lines. The lines labeled "RE" shows the solution under RE, lines labeled "RLS" are the results under decreasing gain RLS learning and lines with " $g=0.03$ " and " $g=0.10 "$ reflect constant gain learning. The results are expressed as deviation (in units as indicated in each figure) from a baseline projection of the model.

In interpreting the results, it is important to stress the key features of the MSG3 model that cause both real and nominal shocks to have more persistence than in most simple theoretical models with perfectly flexible markets. Firstly, the presence of adjustment costs in capital accumulation means investment will be smoothed in the event of shocks. Thus in a large economy like the US, there cannot be perfect consumption smoothing because this requires a flexible supply-side to absorb savings in the form of capital accumulation. ${ }^{7}$ Secondly, nominal rigidities in the model emanate from the wage adjustment model. This model assumes overlapping wage contracts. Thirdly, the model assumes each market comprises agents forming expectations by using the model itself and agents that use a steady state rule-of-thumb for expectations formation. When the RE assumptions are replaced with learning in this model, the feature of rule-of-thumb remains.

\footnotetext{
${ }^{7}$ See McKibbin and Wilcoxen (1998).
} 


\subsection{Inflation Target}

The effects of a persistent increase in the inflation target hinges crucially on the monetary policy reaction function of the US economy. In the MSG3 model, the US policymaker's reaction function follows a Henderson-McKibbin-Taylor (HMT) rule (Henderson and McKibbin, 1993) with the short term nominal interest rate dependent on the lagged interest rate and positively on both the difference between actual and targeted inflation and the difference between actual and desired GDP growth:

$$
i_{t}=i_{t-1}+\alpha\left(\pi_{t}-\bar{\pi}_{t}\right)+\beta\left(\left[y_{t}-y_{t-1}\right]-\left[\overline{y_{t}-y_{t-1}}\right]\right),
$$

where $i_{t}$ is the short term policy interest rate in $t$ and $i_{t-1}$ is the policy interest rate in $t-1 ; \pi_{t}$ is the actual inflation in $t ;\left[y_{t}-y_{t-1}\right]$ is the change in the log of output (or output growth) in $t$. Corresponding barred variables denote desired values of these target variables. The weights in the policy reaction functions are $\alpha=0.5$ and $\beta=0.5$.

Figure (1) shows the dynamic responses of various US variables to a persistent change in the inflation target of 2.97 percentage points since 2006. A persistent increase in the Fed's inflation target will lower the US nominal interest rate. Due to nominal rigidities, the real interest rate will fall in the first year. Within the US, lower real interest rates stimulate investment. Lower real interest rate also leads to a change in the relative price of consumption across time, and thus resulting in an intertemporal shift in consumption from the future to the present. The rise in investment and consumption also raises demand which further increases investment and consumption through the multiplier and accelerator mechanisms caused by backward-looking households and firms.

As the US economy is a large open economy, changes in the real interest rate also affect international linkages. In particular, a prolonged period of low interest rates in the US would tend to lead to capital outflow to the ROW, thus lowering the ROW interest rates in the short run. However, strong domestic demand in the US is supported by the persistent increase in domestic investment and consumption in the short run. The prolonged period of increased consumption and investment can be attributed to the combination of nominal rigidities and adjustment costs in capital accumulation. Higher consumption of both domestic and imported goods, leads to higher imports and a deteriorating US trade balance during the adjustment.

On the other hand, the appreciation of the currency from the point of view of the ROW has significant effects. Consumption of the ROW goods is higher (as reflected by a trade surplus in the ROW during adjustment) because an appreciated real exchange rate allows consumers to import more goods from the US more cheaply in terms of the ROW goods. This terms of trade effect diminishes over time as the real exchange rate moves towards the baseline. The subsequent surplus in the ROW trade balance suggests consumers in the ROW attempt to smooth consumption while real GDP fluctuates due to changes in the level of investment.

Overall, raising the inflation target has positive but temporary transmission effects. 
Under learning, real GDP, consumption and investment in the US economy exhibits deviations from the REE. There are two reasons. First, learning agents are not internalizing the shock since they cannot observe the entire future path of the shock to the inflation target. This differs from the RE outcome where agents have perfect foresight on the exact nature of shock in the future. Second, the time paths of these variables are more volatile as the parameter set characterizing the RE solution is now drifting over time as more information becomes available for agents to update their expectations.

Learning agents seem to have misperceived the correct relation of the inflation target shock to the rest of the model. The real interest rate is no longer tied down in the short run to the rate of time preference in the RE sense. More importantly, the HMT rule enters the VAR learning model structurally. As such, the coefficient of $i_{t-1}, \alpha$ and $\beta$ are now time-varying. The volatile movement in the interest rate is mainly driven by the time path of $\alpha$ which happens to be smaller than that of the RE solution during the transition. Being a type of multivariate learning, the reduced form coefficients of $i_{t-1}, \alpha$ and $\beta$, embedded in $\phi_{1 t}$ and $\phi_{2 t}$, adjust gradually as more data becomes available. This explains the gradual adjustment of interest rate to the baseline. Since the link between the nominal interest rate and inflation target are weaker, learning agents think a low interest rate environment will be conducive for higher consumption and investment in the initial periods. This also leads to higher GDP compared to the REE.

The choice of gain sequence is crucial in the dynamic responses. A higher constant gain leads to a faster speed of learning. This is evident in minimal deviation of the learning time path compared to that of the RE in the interest rate. Since the nominal interest rate is directly affected by the inflation target shock, the rest of the variables adjusts back to baseline with the fastest associated with the high constant gain. The sequential decline in the real interest rate causes consumption and investment to adjust back to the baseline over a long period. In the long run, the transversality conditions and all intertemporal budget constraints are binding, and as such the real variables would tend to return to the REE.

In terms of percentage deviation from baseline, the real exchange rate under learning depreciates less as compared to the RE case in the first year following the impact of the shock. Due to path dependence and learning inertia, the real exchange rate remains less volatile than that in RE. Intuitively, this is associated with less volatile nominal interest rate.

Similar to the US, the real interest rate rises sharply in the ROW. This occurs with a delay as the ROW does not experience the shock directly. Furthermore, under VAR learning, agents attached same weight to each variable indiscriminately. Intuitively, the ROW real GDP should fall. However, strong growth in the US raises demands for the ROW exports which increases the ROW GDP by magnitude greater than the RE case. This causes ROW investment and consumption to rise, and also put upward pressure on the ROW real interest rate. The consumption and investment responses remain strong for a longer duration than under RE. 
Using our definition of policy transmission, the monetary policy change has resulted in a positive spillover effect to the ROW. Thus, this shock is also positively transmitted under adaptive learning. However, the change in the size of the US and the ROW GDPs are more pronounced in the short run which subsequently leads to losses in the medium term as the global economy adjusts back to the baseline asymptotically. This is further substantiated by the longer period of the lowered ROW real GDP.

\subsection{Fiscal Policy}

A demand shock is assumed to be a change in the US total government consumption. Since the MSG3 model incorporates intertemporal accounting, the assumptions about the fiscal closure rules are important. It is assumed that changes in fiscal deficits are sustainable by imposing a lump sum tax on households to cover the additional interest payments from any changes in the long term government debt. Thus a persistent change in government spending will change the long run stock of debt to GDP. This is a standard closure assumption in the MSG3 model. Figure (2) shows the dynamic responses of the US economy after experiencing a positive persistent shock to government consumption of 1.17 percent of GDP in 2006.

The RE benchmark solution can be explained by the standard Mundell-Fleming reasoning. The US real interest rate rises by about $1 \%$ above baseline upon impact in 2006 due to excess demand. This crowds out private expenditure as shown in the consumption profile. Lower investment expenditure also leads to lower level of capital stock in the US.

A bond-financed fiscal expansion, under the assumption of perfect asset substitutability between the US and the ROW financial assets, will lead to a rise in domestic income in the US and an appreciation of the US dollar against the currency of the ROW. Indeed, this is so with US real GDP rising by $0.3 \%$ and its exchange rate appreciating by $1.2 \%$ in 2006. The appreciated US dollar has produced a large trade deficit. It is clear that the increase in real interest rate has crowded out private consumption and private investment, and real exchange rate appreciation has crowded out net exports, albeit the presence of fiscal stimulus and the rise in US GDP.

Fiscal expansion in the US is negatively transmitted in terms of lower ROW real GDP during the transition. This finding is consistent with the result in Bianconi and Turnovsky (1997). ${ }^{8}$ The increase in US government spending financed by issuing debt has led to an increase in the world interest rate. This subsequently dampens the ROW investment. Thus, this policy is beggar-thy-neighbor. On the other hand, the appreciation of the US dollars which translates to a real depreciation of the ROW currency results in a temporary

\footnotetext{
${ }^{8}$ They have also examined the implications of other methods of financing the fiscal deficits. Their result shows that the assumption on the financing scheme changes the nature of international transmission. If the increase in fiscal expenditure is financed by a tax on capital, the transmission effect differs from standard Mundell-Fleming explanation. Under this assumption, the home country experiences a reduction in economic activity while the foreign country gains. If the increase in fiscal expenditure is financed by a tax on labor, the qualitative result is similar to that of a tax on capital. However, there are also plausible cases whereby the effect can be reversed, that is, an expansion in domestic activity and a reduction in foreign activity.
} 
trade surplus for the ROW in the short run. However, this is short-lived as the US real exchange rate depreciates towards the baseline over time. The gradual depreciation can be explained by the sluggish adjustment of nominal wages and prices in both regions.

When agents are learning about the US fiscal expansion, the real interest rate increases by a larger amount in comparison to the RE case. The government consumption variable is embedded within the national income identity (see Appendix B, equation (42)). As we have initialized the parameter matrix $\phi_{2 t}$ at the REE, the only possibility of initial overshooting of output in the first period is due to learning inertia which has made the relationship between output and government consumption more positive. Operating through the HMT rule, this causes nominal interest rate to rise and further increases the real interest rate. This consequently resulted in lower private savings and higher consumption in the short run. This holds for both the RLS and constant gain learning algorithms.

The higher real interest rate also drives down private investment. Under RE, consumers internalize the future tax effect from the current increase in government spending and thus, through revisions in human wealth accumulation, do not raise consumption as much. On the other hand, the lack of information has misled learners to estimate a higher positive effect from the US fiscal expansion. This is reflected by higher consumption in the short run.

Firms also understand the future tax effects under RE. As a result, they use higher future interest rates more heavily to discount the short term output stimulus and this leads to a sharp decline in investment in the short run. Under learning, the misperception of the fiscal multiplier effect on the real interest rate has led to a larger decline in US investment.

Capital flowing from the ROW to the US to reap a higher rate of return also drives up the real interest rate in the ROW. Given that there is a large difference between the real interest rates of the US and the ROW under learning, this leads to larger capital outflow from the ROW. The sum of these effects has caused US real GDP to rise by approximately $1 \%$ above the baseline. This is substantial with respect to the increase of approximately $0.3 \%$ in the $\mathrm{RE}$ outcome. However, as more information is revealed over time, US consumers learn about the true nature of the shock and reduce future consumption.

In contrast to the RE outcome, a rise in the US GDP is now associated with a rise in the ROW GDP because the sharp rise in the US GDP initially dominates the effects of higher real interest rates on the ROW economy. This short run effect, reflected in terms of a hike in the ROW consumption, is quickly reversed as the spike in the real interest rate in the ROW reduces investment and households cut back on consumption after the first year. Thus US fiscal policy continues to crowd out the ROW domestic demand after the first year and leads to prolonged weaknesses in consumption and investment. The transmission mechanism under learning differs from that in Bianconi and Turnovsky (1997), which follow the RE outcome of the MSG3 model. 


\subsection{Productivity Shock}

Figure (3) shows the results for the effects of persistent positive productivity shocks in the two sectors of production (energy and non-energy) in the US economy by 1.21 percentage points in 2006. A sustained period of productivity growth leads to a surge in the US real GDP in the first year, but this gradually decays as the shock diminishes over time. The increase in productivity, which shifts the US production function temporarily outwards, lowers real interest rate in 2006. Through wealth effects, private consumption is tilted to the present.

A low real interest rate and rising marginal product of capital also creates a boom in investment and generates faster capital accumulation which reinforces the increase in productivity. The real exchange rate depreciates in line with the temporary fall in interest rate via the standard interest rate parity condition. It also reflects the fact that the supply of US goods has risen relative to demand, and thus their relative price (the real exchange rate) must fall (depreciate). Capital flows from the US to the ROW as a result of the fall in the US real interest rate and the desire to raise production of the ROW goods for consumption purposes. Moreover, this is consistent with the increase in the US trade balance. Note that the initial response is driven by forward-looking households and firms reacting to reap expected higher future growth prospects. The existence of rule-of-thumb agents has also induced some initial overshooting in the real economy.

Since the gain in US productivity is a free good in the global economy, the transmission effect is positive in terms of wealth creation for the ROW. Despite a trade deficit in the ROW in the first year (which is consistent with the real depreciation of the US dollar), US consumers begin to demand more goods from the ROW and consequently leads to a trade surplus from the third year onwards. Furthermore, the representative household in the ROW holds US assets and is able to benefit from excess profits gained by US firms during the transition period.

In the learning world, productivity shocks enter the wealth of household and the Tobin's q. These affect the consumption and investment profiles respectively (see Appendix B, equations (47) and (48)). For the household, a positive productivity shock increases the firm's demand for labor. Under learning, consumption is less volatile and persistence. This stems from the fact that the associated elements of $\phi_{1 t}$ and $\phi_{2 t}$ are less than that of $\phi_{1}^{R E}$ and $\phi_{2}^{R E}$ respectively.

US investment drops sharply in the first year, contrary to the rise under RE. This can be explained by $\phi_{2 t}>\phi_{2}^{R E}$ which leads to a higher marginal product of capital. This implies less capital is needed for the same level of output. This outcome is also consistent with a longer spell of US trade deficit as foreign debt rises from overseas borrowing. As agents are engaged in one period ahead forecasting, the learning time paths move relatively close to the REE by 2007. Consequently, the decline in the requirement for higher capital stocks leads to a delayed boom in investment, in contrast to the RE case which experiences a surge in investment in the first year. Thus, the productivity shock 
under learning has a negative transmission effect in the ROW. Real GDP falls instead due to negative repercussions on consumption and investment.

\subsection{Equity Risk Premium}

Changes in equity risk premia is found to be one of the important shocks on countries during the Asian Financial Crisis and other recent global shocks (see McKibbin, 1998; McKibbin and Vines, 2000, 2003). The equity risk premium is defined as the difference between the expected return on holding equity and the expected return on holding government bonds. For these simulations, the returns from the US S\&P 500 for equity and that of the US three months T-bills were used to condition this shock. In what follows, the equity risk is increased by 5.358 percentage points in 2006 .

The effect of a change in the equity risk premium works through the intertemporal arbitrage condition for Tobin's $q$. A higher required rate of return on equities can only be achieved by reducing the level of capital stock. Thus, a rise in the risk premium pushes Tobin's $q$ downwards and discourages investment (see Figure (4)). As a result, asset substitution occurs. The representative household will reduce ownership of equities and diversify by holding more government bonds, housing and foreign assets. This causes real interest rates to fall, and housing prices to rise. It also causes a depreciation of the real exchange rate in the first few years as the representative household increases ownership of the ROW assets.

As the representative household holds a portfolio comprising equities, government bonds and housing, there are wealth effects from the capital losses on equities and capital gains from bonds and housing. This explains the increment in consumption in the first few years after the shock has been introduced. Moreover, the fall in the real interest rate during this adjustment period creates an incentive to shift consumption to the present. However, due to liquidity constraints and the costs of adjustment in switching between capital and housing, consumption eventually declines below the baseline before recovering.

The capital outflow from the US is a capital inflow into the ROW. Thus asset prices rise in the ROW and consumption rises attributable to rising wealth effects. Together with this, the inflow of private capital into investment raises aggregate demand and temporarily raises aggregate supply. Consequently, this is reflected in the ROW real GDP trending above the baseline during the transition period. Hence, a rise in the US equity risk premium raises the ROW real growth for a prolonged period. This is the case of a negative transmission since US GDP falls while the ROW GDP rises.

Under learning, interpretation of the transmission of US equity risk premium shock is quite different. This is not surprising given that asset market arbitrage assumptions are critical in the RE story. Yet these are less important under learning. Since Tobin's $q$ depends on expected future increment in the marginal product of physical capital, this expectation evolves according to the underlying adaptive learning algorithms. The simulation result suggests there is less incentive for agents to substitute across the various 
classes of assets in the MSG3 model, leading to higher savings initially. In this case, the reduced form associated elements of $\phi_{1 t}$ is less than that of $\phi_{1}^{R E}$ (see Appendix B, equation (47)). This leads to a lower rate of capital depletion from the increase in equity risk. Thus less asset substitution occurs and leads to a higher than expected real investment rate compared to RE. Nonetheless the shock discourages investment in equity in the US and higher savings initially. This is further substantiated from the decline in US consumption in the short run as shown in Figure (4). But the decline in US investment under learning is less volatile than that under RE. In sum, overall real GDP falls by a smaller magnitude below the baseline compared to the REE. Hence, the real interest rate effect dominates under learning.

The transmission to the ROW is very different under learning. In the RE case, capital flows into the ROW were much larger driving up both investment and consumption. The fall in US GDP causes a fall in the ROW GDP driving down consumption and investment. There are no wealth effects from the capital reallocation across borders, and as such the transmission story is very different.

Amongst the shocks considered, the fall in the ROW real GDP yields the largest difference between the RE and adaptive learning assumptions. This brings out the important role of asset markets in the transmission of shocks in the MSG3 model. When shocks related to asset markets are propagated across borders, the introduction of adaptive learning has created an additional layer of interaction in the dynamic responses. Moreover, this has also changed the transmission mechanism.

\section{Discussion}

To evaluate model fit under learning, the standard deviations of variables obtained using the various learning algorithms adopted in this paper are compared against the RE benchmark. Table (1) shows the standard deviations of key macroeconomic variables for the simulation period of forty years.

From Table (1), it is clear that the choice of learning algorithm and gain sequences makes a difference to the volatilities of variables. For the case of the RLS algorithm, macroeconomic variables experienced significant increment in the standard deviations across various policy changes and shocks. When a low constant gain $\bar{g}=0.03$ was used, these standard deviations fell. This is expected given a low constant gain means learners are using a larger window of observations to update their expectations. Consequently, they are also slow to recognize forecast errors made in the previous period. Meanwhile when a high constant gain $\bar{g}=0.10$ was used, the standard deviations of variables dropped significantly.

Another noteworthy point is that the volatilities of most variables generated using the constant gain learning algorithms with $\bar{g}=0.10$ are close to that of the $\mathrm{RE}$ version of the MSG3 model, especially for the US. Across the gain sequences considered, the effects of learning on the ROW is mixed. 
Given there are mixed results on the choice of learning algorithms in matching the statistical properties of the standard MSG3 model, Table (2) presents the minimum squared errors (MSE) of macroeconomic variables under various learning algorithms and under various scenarios of policy change and shock. The results suggest constant gain learning with $\bar{g}=0.03$ gives the highest MSE for most variables amongst the shock scenarios. Following Evans and Honkapohja (1993), we emphasize that there are interdependencies in the choice of gain sequence. Thus, these are Nash equilibrium gains rather than collective MSE minimizing choice. This, however, suggests the estimate of a low gain of 0.02 obtained in Milani (2006) may not be optimal for the case of learning in the MSG3 model. On the other hand, a high constant gain $\bar{g}=0.10$ yields the best performance in terms of the MSE. Coincidentally, this is close to the calibrated value in Evans and Honkapohja (1993).

Table (3) presents the sign and magnitude of the own-country and cross-country spillover of policy changes in the US and the ROW in the first and the fifth year under $\mathrm{RE}$ and constant gain $\bar{g}=0.10$ learning. Policy changes and shocks are positively transmitted under RE for inflation target and productivity shocks in the first year under RE. Whereas demand and equity risk shocks are negatively transmitted under RE. However, under learning, the signs for the transmission of shocks are opposite to that of the RE results except for the case of inflation target shock. Furthermore, the size of opposite spillover effects are found to be the most significant for the shock to US equity risk premium. This is not surprising since this is a direct shock to the asset markets in which expectations play a critical role.

Table (3) has also reported the multiplier effects for the fifth year to check for sign reversals in the opposite sign uncovered in the initial transmission of shocks. Between the $\mathrm{RE}$ and learning outcomes, the magnitudes of these multipliers are relatively close by the fifth year. The signs have reversed or are close to RE for all shocks except for equity risk. Again, this reiterates the point that learning has a significant impact under an equity risk scenario.

\section{Sensitivity Analysis}

In this section, we consider a number of sensitivity analyses to the baseline model and verify how the results could be affected by different assumptions. First, we consider how the dynamic responses will vary with the degree of initial beliefs endowed to the learners. As shown in Carceles-Poveda and Giannitsarou (2006), initial conditions matter for learning algorithms. Second, we investigate the effects of the proportion of forwardand backward-looking agents in the MSG3 model. This proportion determines the degree of nominal rigidities, an element as argued by many macroeconomists to be essential for matching the model to data. Milani (2006) demonstrates that when RE is replaced by learning, the estimated degrees of nominal rigidities fall to zero. Third, we examine the effects of different gain sequences for the US and the ROW. In particular, we explore 
scenario in which learners in the ROW are learning at a relatively slower speed than learners in the US. In what follows, we focus on the responses of the real GDPs since this is our main definitions on effects of international transmission of shocks.

\subsection{Different Initial Beliefs}

In the baseline learning model, we have assumed the initial beliefs of agents to be at the REE. Table (4) shows the effects of initializing the RLS and constant gain algorithms at $5 \%$ below and above the RE solution $\bar{\phi}=\left(\phi_{1}^{R E}, \phi_{2}^{R E}\right)$ for the international transmission of shocks in the first and fifth year. As reflected in the table, it appears that the level of the initial values for $\bar{\phi}$ has not changed the signs of the international transmission of shocks in the first year as shown in earlier sections. This finding is robust to the learning algorithms chosen. We also find that initializing $\phi_{0}$ above the $\bar{\phi}$ leads to a larger response on the US economy under the scenarios of inflation target and fiscal policy. The opposite holds for that of productivity and equity risk shocks. For the fifth year, the simulated results are close to that of the REE across various initial values of $\phi_{0}$.

\subsection{Proportion of Forward- and Backward-Looking Agents}

It is well known that the dynamic stochastic general equilibrium (DSGE) models have difficulties in matching the behavior and persistence of observed macroeconomic variables. Researchers working on these models found that substantial degrees of nominal rigidities and habit persistence are essential for bringing the model to data (for example, Christiano et al., 2005). This feature can also be found in the MSG3 model. This takes the form of adjusting the behavior of consumers and firms to allow for short run deviations from intertemporal optimizing conditions. The baseline model assumes the fraction of forwardlooking agents to be 0.3. We investigate the effects of learning when the fraction of forward-looking agents is assumed to be 0.7 .

Figure (5) contrasts the simulation results for cases in which the fraction of forwardlooking agents differs across various shock scenarios and various learning algorithms. The left column summarizes the dynamics of real GDPs for the two countries under RE and various adaptive learning algorithms. These are obtained using the standard assumption on the fraction of forward-looking agents being 0.3. The right column shows the results under the case in which this fraction is 0.7 . Increasing the fraction of forward-looking agents has led to a correction in the opposite signs for international transmission of shocks for all cases except for equity risk premium. This suggests the importance of introducing learning as a source of endogenous persistence in the analysis, reinforcing the findings in Milani (2006).

\subsection{Different Learning Speeds Across Countries}

So far, we have assumed that agents operating in this world economy are learning the law of motions of different variables from different countries at the same rate. Here, we relax 
this assumption by imposing different speeds for the learners in the US and the ROW. In particular, we have imposed $\bar{g}_{U S}=0.10$ and $\bar{g}_{R O W}=0.03$ since US learners will be more alert to shock in their home economy. Since the ROW does not experience the shock directly, it is less necessary for the ROW to learn at a high speed. Figure (6) shows the real GDPs of the US and the ROW for the baseline cases and $\bar{g}_{U S}=0.10$ and $\bar{g}_{R O W}=0.03$, denoted by "gh \& gf". The results show that the signs of international transmission of shocks remain the opposite to the $\mathrm{RE}$ solution.

\section{Conclusion}

This paper contributes to the literature on the international transmission of shocks and policy changes by comparing the nature of the transmission process when agents are assumed to have $\mathrm{RE}$ versus when agents form expectations through adaptive learning. The analysis was undertaken in an established empirical macroeconomic model, the MSG3 model. The policy changes and shocks explored are inflation target, fiscal policy, productivity shocks and equity risk premium. Amongst the shocks considered, the initial transmission effects under learning have opposite signs, compared to RE, except for changes in the monetary/inflation target in the short run. This is expected due to adjustment inertia and self-referential features of learning models. The opposite signs found in the initial transmission effects of shocks under learning are reverted once we increase the fraction of forward-looking agents in the model. This holds for all cases except for equity risk. This finding suggests learning dynamics are sensitive to the degree of nominal rigidities in the global economy.

Given the significant deviation of variables from the RE benchmark, this reiterates the importance of expectations in macroeconomic modeling. In particular, it also highlights the effects of portfolio allocation in the MSG3 class of intertemporal models as agents substitute across asset classes and across borders after a shock has been imposed. More importantly, macroeconomic variables are found to exhibit greater volatilities during the transition when agents are learning.

The results from this paper reinforce the role of asset markets in the international transmission of shocks in the MSG3 model and just how important expectations assumption are, especially through this channel. In the RE benchmark, asset prices accurately reflect the expected future returns of assets. In the adaptive learning world, this channel changes fundamentally as expectations evolve over time. Furthermore, the biggest difference can be found under the scenario of an increase in equity risk premium, which is not surprising since this is a shock emanating from the asset markets. 


\section{A A stylized 2 country G-Cubed model}

This appendix presents a stylized two-country, two-sectors version of the G-cubed model in McKibbin and Wilcoxen (1999). There are two symmetrical countries - the US and the ROW. The empirical feature of the US economy follows that of the G-cubed model. For simplicity, the ROW is assumed to be a mirror image of the US economy. Each country is populated by various category of economic agents. These are households, the government, the financial sector and two firms from the two sectors of production. The two sectors of production are energy and non-energy. This follows closely to the level of aggregation in the MSG2 model in McKibbin and Sachs (1991). The parameter estimates are aggregated from the twelve sectors to the two sectors in this stylized model. Furthermore, in order to preserve symmetry, the initial level of foreign debt of each country is assumed to be zero.

In what follows, all quantity variables are written in terms of efficiency labor units. As such, the long run steady state of the model is on the balanced growth path in the context of a neoclassical Swan/Solow/Ramsey growth model.

\section{A.1 Firms}

In each sector of production, there is a representative price-taking firm which will choose an optimal combination of inputs and level of investment to maximize its market value in the equity market. The four factors of production are capital, labor, energy and materials. The production function of this firm follows a constant elasticity of substitution (CES) function:

$$
Q_{i}=A_{i}^{o}\left(\sum_{j=\text { k.l.e.m }}\left(\delta_{i j}^{o}\right)^{\frac{1}{\sigma_{i}^{o}}} x_{i j}^{\frac{\sigma_{i}^{o}-1}{\sigma_{i}^{o}}}\right)^{\frac{\sigma_{i}^{o}}{\sigma_{i}^{o}-1}}
$$

where $Q_{i}$ is the output of sector $i, x_{i j}$ is sector $i$ 's demand for input $j$ (that is, output in sector $j$ ), and $A_{i}^{o}, \delta_{i j}^{o}$, and $\sigma_{i}^{o}$ are parameters obtained econometrically following McKibbin and Wilcoxen (1999). The parameter $A_{i}^{o}$ signifies the level of technology in sector $i, \sigma_{i}^{o}$ is the elasticity of substitution, and the parameters $\delta_{i j}$ reflect the weights of different inputs in the production function. The notation of superscript $o$ indicates that the parameters apply to the output tier. The sum of $\delta_{i j}^{o}$ is constrained to one.

The goods and services purchased by each firm are aggregates of imported and domestically produced commodities. These are assumed to be imperfect substitutes via the choice of a CES production function. Agents in the respective economy are assumed to have identical preference between domestic and foreign variant of each commodity. In turn, these preferences are defined over composite commodities made from domestic and imported goods and services. Similar to the production function, each of these commodities, $Y_{i}$, follows a CES function of inputs from domestic output $Q_{i}$, and an aggregate of goods imported from the ROW, $M_{i}$ : 


$$
y_{i}=A_{i}^{f d}\left(\left(\delta_{i d}^{f d}\right)^{\frac{1}{\sigma_{i}^{f d}}} Q_{i}^{\frac{\sigma_{i}^{f d}-1}{\sigma_{i}^{f d}}}+\left(\delta_{i f}^{f d}\right)^{\frac{1}{\sigma_{i}^{f d}}} M_{i}^{\frac{\sigma_{i}^{f d}-1}{\sigma_{i}^{f d}}}\right)^{\frac{\sigma_{i}^{f d}}{\sigma_{i}^{f d}-1}}
$$

where $\sigma_{i}^{f d}$ is the elasticity of substitution between domestic and foreign goods (Armington, 1969). The aggregate imported good, $M_{i}$, is itself a CES composite of imports from the ROW, $M_{i c}$, where $c$ is an index indicating the country of origin:

$$
M_{i}=A_{i}^{f f}\left(\left(\delta_{i c}^{f d}\right)^{\frac{1}{\sigma_{i}^{f f}}} M_{i c}^{\frac{\sigma_{i}^{f f}-1}{\sigma_{i}^{f f}}}\right)^{\frac{\sigma_{i}^{f f}}{\sigma_{i}^{f f}-1}}
$$

The elasticity of substitution between imports from the ROW is $\sigma_{i}^{f f}$.

Since all agents in the model have same preferences over the origin of goods and services, the energy and non-energy sectors will have the identical preferences over domestically produced and imported oil. ${ }^{9}$ This treatment conforms with the input-output data used. Moreover, this is tractable as production, consumption and investment decisions can be nested easily.

In each sector, the law of motion for the capital depends on the rate of fixed capital formation $\left(J_{i}\right)$ and the rate of depreciation $\left(\delta_{i}\right)$ :

$$
\dot{k_{i}}=J_{i}-\delta_{i} k_{i}
$$

Following the standard treatment in costs of adjustment models (see Lucas, 1967; Treadway, 1969; Uzawa, 1969), the process of investing in new capital is subjected to rising marginal costs of installation. In what follows, the Uzawa's approach was adopted. This assumes that the representative firm in sector $i$ needs to purchase a large quantity, $I$, to install $J$ units of capital. In turn, the quantity of $I$ purchased depends on the rate of investment, $\left(\frac{J}{k}\right)$. The level of investment is given by:

$$
I_{i}=\left(1+\frac{\phi_{i}}{2} \frac{J_{i}}{k_{i}}\right) J_{i}
$$

where $\phi_{i}$ is a non-negative parameter. The variable $J$ can be interpreted as installation services provided by the supplier of capital goods. Note that the difference in the sectorspecific requirements of capital in the two industries is reflected in terms of different values for $\phi_{i}$.

Having established the functional forms of production functions and investment, the objective of each firm is to choose an optimal level of investment and optimal combination of the other three factors of production (labor, materials and energy) to maximize

\footnotetext{
${ }^{9}$ It is not essential for both sectors to purchase the same quantity of oil. The key point is that both sectors are indifferent to the origins of the oil bought.
} 
intertemporal net-of-tax profits. For analytical tractability, certainty equivalence is imposed. As such, this intertemporal optimization problem becomes deterministic. Thus, the firm maximizes ${ }^{10}$ :

$$
\int_{t}^{\infty}\left(\pi_{i}-\left(1-\tau_{4}\right) p^{I} I_{i}\right) \exp ^{[-(R(s)-n)(s-t)]} d s
$$

where all variables are implicitly subscripted by time. The firm's profits, $\pi$, are given by:

$$
\pi_{i}=\left(1-\tau_{2}\right)\left(p_{i}^{*} Q_{i}-w_{i} x_{i l}-p_{i}^{e} x_{i e}-p_{i}^{m} x_{i m}\right)
$$

where $\tau_{2}$ is the corporate income tax, $\tau_{4}$ is an investment tax credit, and $p^{*}$ is the producer price of the firm's output. The long term interest rate, $R_{s}$ between time $t$ and $s$ is obtained by:

$$
R(s)=\frac{1}{s-t} \int_{t}^{s} r(v) d v
$$

As all real variables are expressed in efficiency labor units in this model, the firm's profits have to be discounted by a suitable discount factor. This discount factor has to be adjusted for the rates of population and productivity growth, $n$. In this model, the value of $n$ is assumed to be $2.5 \%$ per annum. The following first order conditions characterizes the firm's behavior in equilibrium:

$$
\begin{gathered}
x_{i j}=\delta_{i j}^{o}\left(A_{i}^{o}\right)^{\sigma_{i}^{o}-1} Q_{i}\left(\frac{p_{i}^{*}}{p_{j}}\right)^{\sigma_{i}^{o}}, j \in\{l, e, m\} \\
\lambda_{i}=\left(1+\phi_{i} \frac{J_{i}}{k_{i}}\right)\left(1-\tau_{4}\right) p^{I} \\
\frac{d \lambda_{i}}{d s}=\left(r+\delta_{i}\right) \lambda_{i}-\left(1-\tau_{2}\right) p_{i}^{*} \frac{d Q_{i}}{d k_{i}}-\left(1-\tau_{4}\right) p^{I} \frac{\phi_{i}}{2}\left(\frac{J_{i}}{k_{i}}\right)^{2}
\end{gathered}
$$

where $\lambda_{i}$ is the shadow price of an additional unit of investment in sector $i$.

Equation (9) is the firm's demands for labor, energy and materials. Equations (10) and (11) describe the optimal time path of capital stock. Integration of (11) along the optimum time paths of investment and capital accumulation, $\widehat{J}(t)$ and $\widehat{k}(t)$ yields the explicit expression for $\lambda_{i}$ :

\footnotetext{
${ }^{10}$ Note that the rate of growth of the economy's endowment of effective labor units, $n$, appears in the discount factor. This is required given that the quantity and value variables in the model have been scaled by the number of effective labor units. To obtain these variables in original form, they have to be multiplied by $\exp (n t)$.
} 


$$
\lambda_{i}(t)=\int_{t}^{\infty}\left(\left.\left(1-\tau_{2}\right) p_{i}^{*} \frac{d Q_{i}}{d k_{i}}\right|_{\widehat{J}, \widehat{k}}+\left(1-\tau_{4}\right) p^{I} \frac{\phi_{i}}{2}\left(\frac{\widehat{J}_{i}}{\widehat{k}_{i}}\right)^{2}\right) \exp ^{-(R(s)+\delta)(s-t)} d s
$$

Equation (12) comprises of two components and they are interpreted as follows. The first term in the integral is the present discounted value of after-tax marginal product of capital obtained from the production function. The second term is the savings derived from the adjustment costs of additional capital. Note that this term is net of the investment tax. The expression for $\lambda_{i}$ in equation (10) is related to the after-tax version of Tobin's $q$ (see Abel, 1979), this becomes:

$$
q_{i}=\frac{\lambda_{i}}{\left(1-\tau_{4}\right) p^{I}}
$$

Consequently, equation (10) is rewritten as:

$$
\frac{J_{i}}{k_{i}}=\frac{1}{\phi_{i}}\left(q_{i}-1\right)
$$

Upon substitution of this expression into (5) yields the total purchases of new capital goods:

$$
I_{i}=\frac{1}{2 \phi_{i}}\left(q_{i}^{2}-1\right) k_{i}
$$

As shown in Hayashi (1979), actual investment is partially driven by cash flows. To account for this feature, equation (5) is written as a weighted average of $q$ and the firm's current cash flow at time $t, \pi_{i}$, adjusted for the investment tax credit:

$$
I_{i}=\alpha_{2} \frac{1}{2 \phi_{i}}\left(q_{i}^{2}-1\right) k_{i}+\left(1-\alpha_{2}\right) \frac{\pi_{i}}{\left(1-\tau_{4}\right) p^{I}}
$$

There are two benefits for writing equation (16) in this manner. First, it improves the model's ability to mimic historical data. Second, it reflects the fact that some firms are constrained and not able to borrow. As such, these firms invest out of their retained earnings.

Having examined the demand for investment goods by each sector, the supply of investment goods in this model is explained. These goods are supplied by a third industry which uses labor and outputs from the other industries to produce raw capital goods. Similar, the production function of this firm follows closely to that of the other two industries. To be specific, this firm has a nested CES production function which depends on inputs of capital, labor, energy and materials, and earns zero profits. It is also assumed that this firm incurs adjustment costs in the accumulation of capital just like firms in the other industries. However, the data used to estimate this firm's production coefficients is different, that is, the investment column of the input-output table was used. 


\section{A.2 Households}

Households supply labor, save and consume goods and services. Within each region, the household's behavior is modeled by a representative agent having an intertemporal utility function:

$$
U_{t}=\int_{t}^{\infty}(\ln c(s)+\ln g(s)) \exp ^{-\theta(s-t)} d s
$$

where $c(s)$ is the household's aggregate consumption of goods and services at time $s, g(s)$ is the government consumption at $s$, and $\theta$ is the rate of time preference. ${ }^{11}$ The household's intertemporal optimization problem is to maximize (17) subject to the budget constraint in which the present value of consumption is equal to the sum of human wealth, $H$, and initial financial assets, $F^{12}$ :

$$
\int_{t}^{\infty} p^{c}(s) c(s) \exp ^{-(R(s)-n)(s-t)}=H_{t}+F_{t}
$$

Human wealth is defined as the expected present value of the future stream of after-tax labor income plus transfers:

$$
H_{t}=\int_{t}^{\infty}\left(1-\tau_{1}\right)\left(W\left(L^{C}+L^{I}+L^{G}+\sum_{i=1}^{12} L^{i}\right)+T R\right) \exp ^{-(R(s)-n)(s-t)} d s
$$

where $\tau_{1}$ is the tax rate on labor income, $T R$ is the level of government transfers, $L^{C}$ is the quantity of labor used directly in final consumption, $L^{I}$ is labor used in producing the investment good, $L^{G}$ is government employment, and $L^{i}$ is employment in sector $i$. Financial wealth of representative agent is the sum of real money balances, $M O N / P$, real government bonds in the hand of the public, $B$, net holding of claims against foreign residents, $A$, the value of capital in each sector:

$$
F=\frac{M O N}{p}+B+A+q^{I} k^{I}+q^{c} k^{c}+\sum_{i=1}^{12} q^{i} k^{i}
$$

The solution to this maximization problem yields the standard result in which aggregate consumption spending is equal to a constant proportion of private wealth, defined as the sum of human wealth and financial wealth. This solution is expressed mathematically as:

$$
p^{c} c=\theta(F+H)
$$

\footnotetext{
${ }^{11}$ This choice of this functional specification implies that the allocation of expenditure by the household over different goods can be separable in different period in time.

${ }^{12}$ As before, $n$ appears in (18) because the model's scaled variables have to be converted back to their original form.
} 
Following the evidence cited in Campbell and Mankiw (1990) and Hayashi (1982), a fraction of the consumers are assumed to be liquidity-constrained and as such only able to consume a fixed fraction $\gamma$ of their after-tax income $(I N C) .{ }^{13}$ The rest of the consumers are assumed to be full intertemporal optimizers and are not liquidity-constrained. As such, they choose the optimal level of consumption based on (18). The total consumption expenditure is given by:

$$
p^{c} c=\alpha_{8} \theta\left(F_{t}+H_{t}\right)+\left(1-\alpha_{8}\right) \gamma I N C
$$

The share of households $\left(1-\alpha_{8}\right)$ consuming the fixed fraction of their income $\gamma$ could also be interpreted as a form of permanent income behavior in which household expectations about income are myopic.

After determining the overall level of consumption, spending is allocated among goods and services using a CES utility function. ${ }^{14}$ The demand equations for capital, labor, energy and materials can be shown to be:

$$
p_{i} x_{i}^{c}=\delta_{i}^{c} y\left(\frac{p^{c}}{p_{i}}\right)^{\sigma_{c}^{o}-1}, i \in\{k, l, e, m\}
$$

where $y$ is total expenditure, $x_{i}^{c}$ is household demand for good $i, \sigma_{c}^{o}$ is the top-tier elasticity of substitution and the $\delta_{i}^{c}$ are the input-specific parameters of the utility function. The consumption price index, $p^{c}$, is:

$$
p^{c}=\left(\sum_{j=k, l, e, m} \delta_{j}^{C} p_{j}^{\sigma_{C}^{o}-1}\right)^{\frac{1}{\sigma_{C}^{o}-1}}
$$

Household capital services consist of the service flows of consumer durables plus residential housing. The supply of household capital services is determined by consumers themselves who invest in household capital, $k^{c}$, in order to generate a desired flow of capital services, $c^{k}$, according to the following production function:

$$
c^{k}=\alpha k^{c}
$$

where $\alpha$ is a constant. Accumulation of household capital is subject to the condition:

\footnotetext{
${ }^{13}$ There has been considerable debate about the empirical validity of the permanent income hypothesis. In addition to Campbell and Mankiw (1990) and Hayashi (1982), other key papers include Hall (1978), and Flavin (1981). One disadvantage of this specification is equivalent variation cannot be computed. Since the bebavior of some of the households is inconsistent with (21), either because the households are at corner solutions or for some other reason, aggregate behavior is inconsistent with the expenditure function derived from the utility function in (17).

${ }^{14} \mathrm{~A}$ consequence of the CES function is that it imposes income elasticities. This restriction may be rejected by the US data. An alternative would be to replace this functional form with one derived from the linear expenditure system.
} 


$$
\dot{k^{c}}=J^{c}-\delta^{c} k^{c}
$$

Similar to the firm's capital stock, the household capital stock is assumed to be subjected to adjustment costs. Thus, household's spending on investment, $I^{c}$, is related to $J^{c}$ by:

$$
I^{c}=\left(1+\frac{\phi^{c}}{2} \frac{J^{c}}{k^{c}}\right) J^{c},
$$

where $J^{c}$ is the unit of capital to be installed. Therefore, the household's investment decision is to choose $I^{c}$ to maximize:

$$
\int_{t}^{\infty}\left(p^{c k} \alpha k^{c}-p^{I} I^{c}\right) \exp ^{-(R(s)-n)(s-t)} d s
$$

where $p^{c k}$ is the imputed rental price of household capital. In contrast to the firm's investment decision, the key difference is that no variable factors are used in producing household capital services and there is no investment tax credit for household capital. Given these differences, the marginal value of a unit of household capital, $\lambda_{c}$, is shown to be:

$$
\lambda_{c}(t)=\int_{t}^{\infty}\left(p^{c k} \alpha+p^{I} \frac{\phi_{c}}{2}\left(\frac{\widehat{J}_{c}}{\widehat{k}_{c}}\right)^{2}\right) \exp ^{-(R(s)+\delta)(s-t)} d s
$$

where the integral is computed along the optimal path of investment and capital accumulation, $\widehat{J}_{C}(t)$ and $\widehat{k}_{C}(t)$. Marginal $q$ is:

$$
q_{c}=\frac{\lambda_{c}}{p^{I}}
$$

and investment is given by:

$$
\frac{J_{c}}{k_{c}}=\frac{1}{\phi_{c}}\left(q_{c}-1\right)
$$

\section{A.3 The Labor Market}

Labor is assumed to be perfectly mobile across sectors in each region but is assumed to immobile between the two regions. As a result, wages will be the same across sectors within the US, but in general will be different in the ROW. Thus, wages will be equal across sectors within each region, but will generally not be equal between the two regions. In the long run, labor supply is completely inelastic and is determined by the exogenous rate of population growth. Long run wages adjust in each region so that full level of employment can be attained. In the short run, nominal wages are assumed to adjust slowly according to overlapping wage contracts model. To be specific, wages are set based on current wages, the ratio of expected inflation to current inflation, the ratio of current 
inflation to lagged inflation, and the ratio of current employment to full employment:

$$
w_{t+1}=w_{t}\left(\frac{p_{t+1}^{c}}{p_{t}^{c}}\right)^{\alpha_{5}}\left(\frac{p_{t}^{c}}{p_{t-1}^{c}}\right)^{1-\alpha_{5}}\left(\frac{L_{t}}{\bar{L}}\right)^{\alpha_{6}}
$$

The weight that wage contracts attach to expected changes in the price level is $\alpha_{5}$ while the weight assigned to deviations from full employment $(\bar{L})$ is $\alpha_{6}$. Since wages are preset one period in advance, equation (32) can result in short run unemployment if unexpected shocks cause the real wage to become too high for the labor market to clear.

\section{A.4 The Government}

For each region, the real government spending on goods and services is assumed to be exogenous and is allocated among inputs in fixed proportion. In this version of the model, these proportions are based on the US data in 1996. Total government expenditure compromises of purchases of goods and services plus interest payments on government debt, investment tax credits and transfers to households. Government revenue are collected from sales taxes, corporate and personal income taxes, and from the sales of new government bonds. The government budget constraint is written in terms of the accumulation of public debt as:

$$
\dot{B}_{t}=D_{t}=r_{t} B_{t}+G_{t}+T R_{t}-T_{t}
$$

where $B$ is the stock of debt, $D$ is the budget deficit, $G$ is total government spending on goods and services, $T R$ is transfer payments to households, and $T$ is total tax revenue net of any investment tax credit.

In order to prevent the per capita government to grow at a faster rate than the interest rate forever, the following transversality condition is imposed:

$$
\lim _{s \rightarrow \infty} B(s) \exp ^{-(R(s)-n) s}=0
$$

If the government is fully leveraged at all times, (34) allows (33) to be written in integral as:

$$
B_{t}=\int_{t}^{\infty}(T-G-T R) \exp ^{-(R(s)-n)(s-t)} d s
$$

Thus, the current level of debt will always be exactly equal to the present value of future budget surpluses. ${ }^{15}$

The implication of (35) is that a government running a budget deficit today must run an equivalent budget surplus some point in the future. Thus, Ricardian equivalence holds. Otherwise, the government would be unable to service interest payments on the debt issued

\footnotetext{
${ }^{15}$ Strictly speaking, public debt must be less than or equal to the present value of future budget surpluses. For tractability, the government is initially assumed to be fully leveraged and as such, this constraint holds with equality.
} 
and agents would not be willing to hold it given the lack of certainty in returns. To ensure that (35) holds every period, the government levies a lump sum tax in each period equal to the value of interest payments on the outstanding debt. ${ }^{16}$ Thus, this effectively means that any increment in the government debt has to be financed by consols, and future taxes have to be raised in sufficient amount to service any increased in the costs of interest payments.

\section{A.5 Financial Markets and the Balance of Payments}

The two regions in the model are linked by international flows of goods and assets. Flows of goods are determined by the import demands described earlier. These demands are summarized by a set of bilateral trade matrices which map the flows of each good between the exporting and importing countries.

Trade imbalances are financed by flows of assets between countries. Each region with a current account deficit will have a matching capital account surplus, and vice versa. ${ }^{17}$ As such, balance of payments holds in every point in time. Asset markets are also assumed to be perfectly integrated across regions. ${ }^{18}$ Under perfect mobility of capital across borders, expected returns on loans denominated in the currencies of the two regions must be equalized in every period according to a set of interest arbitrage conditions:

$$
i_{U S}+\mu_{U S}=i_{R O W}+\mu_{R O W}+\frac{\dot{E}_{U S}^{R O W}}{E_{U S}^{R O W}}
$$

where $i_{U S}$ and $i_{R O W}$ are the interest rates in the US and the ROW, $\mu_{U S}$ and $\mu_{R O W}$ are exogenous risk premiums demanded by investors (calibrated in the baseline to make the model condition hold exactly with actual data), and $E_{U S}^{R O W}$ is the nominal exchange rate between the currencies of the two countries.

Capital flows may take the form of portfolio investment or foreign direct investment. Nonetheless these are assumed to be perfect substitutes ex ante, adjusting to the expected rates of return across the two countries and across the two sectors. Within each country, the expected returns to each type of asset are equalized by arbitrage conditions. This also accounts for the costs of adjusting physical capital stock and for exogenous risk premia. Since it is costly to adjust physical capital, the inflow of financial capital invested in the form of physical capital in the other country will also be costly. As a result, this model is able to generate features of windfalls gains and/or losses to owners of physical capital. Furthermore, ex post returns can vary significantly across countries and across sectors.

\footnotetext{
${ }^{16}$ In the model the tax is actually levied on the difference between interest payments on the debt and what interest payments would have been if the debt had remained at its base level. The remainder, interest payments on the baseline debt, is financed by ordinary taxes.

${ }^{17}$ Global net flows of private capital are constrained to be zero at all times, that is, the total of all funds borrowed is equal to the total funds lent. On a theoretical basis, this may be plausible, but this assumption is often violated in international financial data.

${ }^{18}$ The mobility of international capital is a subject of considerable debate; see Gordon and Bovenberg (1994) or Feldstein and Horioka (1980) for discussion.
} 


\section{A.6 Money Demand}

Money enters the model through a constraint on transactions. ${ }^{19}$ The demand for real money balances depends on the value of aggregate output and short term nominal interest rates:

$$
M O N=P Y i^{\varepsilon}
$$

where $Y$ is the aggregate level of output, $P$ is the price index for $Y, i$ is the short term interest rate, and $\varepsilon$ is the interest elasticity of money demand. The supply of money is determined by the balance sheet of the central bank and is assumed to be exogenous.

\section{B Equilibrium Conditions}

The two sectors of productions are denoted by subscript $i$, and the two countries denoted by superscript $j$. The log-linearised equilibrium conditions expressed in terms of state and exogenous variables are:

$$
\begin{gathered}
k_{i, t+1}^{j}=J_{i, t}^{j}+(1-p 16 u-g r 1-g r 2) k_{i, t}^{j} \\
Q_{i, t+1}^{j}=Q_{i, t}^{j}+p 13 u\left(\frac{\lambda_{i, t}^{j}}{\left(1-\tau_{4}\right)\left(P^{I}\right)_{i, t}^{j}}-Q_{i, t}^{j}\right) \\
B_{t+1}^{j}=D_{t}^{j}+(1-g r 1-g 2) B_{t}^{j} \\
i_{t}^{j}=i_{t-1}^{j}+\alpha^{j}\left(\pi_{t}-\bar{\pi}_{t}\right)+\beta^{j}\left(\left[y_{t}-y_{t-1}\right]-\left[\overline{y_{t}-y_{t-1}}\right]\right) \\
y_{t}^{j}=C_{t}^{j}+I_{t}^{j}+G_{t}^{j}+X_{t}^{j}-I M_{t}^{j} \\
P_{t}^{j}=\sum_{i=1}^{2} s 18_{i}^{j} P_{i, t}^{j} \\
w_{t+1}^{j}=w_{t}^{j}\left(\frac{p_{t+1}^{j, c}}{p_{t}^{j, c}}\right)^{\alpha_{5}^{j}}\left(\frac{p j_{, t}^{c}}{p_{t-1}^{j, c}}\right)^{1-\alpha_{5}^{j}}\left(\frac{L_{t}^{j}}{\bar{L}^{j}}\right)^{\alpha_{6}^{j}}
\end{gathered}
$$

asset payment ${ }_{t+1}^{U S, R O W}=(1-$ gr $1-$ gr 2$)$ asset payment $t_{t}^{U S, R O W}-$ current account $_{t}^{R O W}$

\footnotetext{
${ }^{19}$ Unlike the other components of the model, this is an assumption. Money demand can be derived from optimization under various assumptions. For instance, money in utility function (see Obstfeld and Rogoff, 1996).
} 


$$
q_{t+1}=q_{t}-r_{t}^{R O W}+r_{t}^{U S}-\xi_{t}^{R O W},
$$

where $\xi_{t}^{R O W}$ is an exchange rate risk premium.

$$
\frac{d \lambda_{i}^{j}}{d t}=\left(1+r_{t}^{j}+\zeta_{t}^{j}+\delta_{i}^{j}\right) \lambda_{i}-\left(1-\tau_{2}\right) p_{i}^{*} \frac{d Q_{i}}{d k_{i}}-\left(1-\tau_{4}\right) p^{I} \frac{\phi_{i}}{2}\left(\frac{J_{i}}{k_{i}}\right)^{2}
$$

where $\zeta_{t}^{j}$ is the equity risk premium.

$$
H_{t+1}^{j}=\left(1+p 2^{j}+r_{t}^{j}-g r 1\right) H_{t}^{j}-\left(1-\tau_{1}\right)\left[w_{t}^{j}\left(L_{t}^{c, j}+L_{t}^{I, j}+L_{t}^{G, j} L_{i, t}^{, j}\right)+T R_{t}^{j}\right]
$$

\section{References}

[1] Abel, A., 1979. Investment and the Value of Capital. Garland, New York.

[2] Armington, P., 1969. A Theory of Demand for Products Distinguished by Place of Production. IMF Staff Papers 16, 159 - 176.

[3] Bianconi, M., Turnovsky, S.J., 1997. International Effects of Government Expenditure in Interdependent Economies. Canadian Journal of Economics 30(1), 57 - 84.

[4] Blanchard, O.J., Fischer, S., 1989. Lectures on Macroeconomics, MIT Press, Cambridge, Massachusetts.

[5] Blanchard, O., Kahn, C. M., 1980. The Solution of Linear Difference Models under Rational Expectations. Econometrica 5, 1305 - 1312.

[6] Bryant, R., Henderson, D., Holtham, G., Hooper, P., Symansky, S., 1988. Empirical Macroeconomics for Interdependent Economies (Eds.). The Brookings Institution, Washington, D.C.

[7] Campbell, J., Mankiw, N.G., 1987. Permanent Income, Current Income and Consumption. NBER Working Paper No. 2436.

[8] Carceles-Poveda, E., Giannitsarou, C., 2006. Adaptive Learning in Practice. Journal of Economic Dynamics and Control, forthcoming.

[9] Christiano, L.J., Eichenbaum, M., Evans, C.L., 2005. Nominal Rigidities and the Dynamic Effects of a Shock to Monetary Policy. Journal of Political Economy 113(1), $1-45$.

[10] Evans, G.W., Honkapohja, S., 2001. Learning and Expectations in Marcoeconomics, Princeton University Press, Princeton, New Jersey.

[11] Evans, G.W., Honkapohja, S., 1998. Economic Dynamics with Learning: New Stability Results. Review of Economic Studies 65, 23 - 44. 
[12] Evans, G.W., Honkapohja, S., 1993. Adaptive Forecasts, Hysteresis, and Endogenous Fluctuations. Federal Reserve Bank of San Francisco Economic Review 1, 3 - 13.

[13] Feldstein, M., Horioka, C., 1980. Domestic Saving and International Capital Flow. Economic Journal 90(June), 314 - 329.

[14] Flavin, M., 1981. The Adjustment of Consumption to Changing Expectations about Future Income. Journal of Political Economy 89, 974 - 1009.

[15] Frenkel, J.A., Razin, A., 1986. The International Transmission and Effects of Fiscal Policies. American Economic Review 76(2), 330 - 335.

[16] Garratt, A., Hall, S.G., 1997. E-equilibria and Adaptive Expectations: Output and Inflation in the LBS model. Journal of Economic Dynamics and Control 21, 1149 1171.

[17] Gordon, R.H., Bovenberg, A.L., 1996. Why is Capital so Immobile Internationally? Possible Explanations and Implications for Capital Income Taxation. American Economic Review 86(5), 1057 - 1075.

[18] Hall, R.E., 1978. Stochastic Implications of the Life-cycle Hypothesis: Theory and Evidence. Journal of Political Economy 86, 971 - 987.

[19] Hall, S.G., Garratt, A., 1995. Model Consistent Learning and Regime Switching in the London Business School Model. Economic Modelling 12(1), 87 - 95.

[20] Hayashi, F., 1979. Tobin's Marginal q and Average q: A Neoclassical Interpretation. Econometrica 50, 213 -224.

[21] Hayashi, F., 1982. The Permanent Income Hypothesis: Estimation and Testing by Instrumental Variables. Journal of Political Economy 90(4), 895 - 916.

[22] Henderson, D.W., McKibbin, W.J., 1993. A Comparison of Some Basic Monetary Policy Regimes for Open Economies: Implications of Different Degrees of Instrument Adjustment and Wage Persistence. Rochester-Carnegie Conference Series on Public Policy 39, 221 - 318.

[23] Jorgenson, D.W., Wilcoxen, P.J., 1990. Environmental Regulation and US Economic Growth. Rand Journal 21(2), 314 - 340.

[24] Lucas, R.E., 1967. Adjustment Costs and the Theory of Supply. Journal of Political Economy 75(4), 321 - 334.

[25] McCallum, B.T., 1983. On Nonuniqueness in Linear Rational Expectations Models: An Attempt at Perspective. Journal of Monetary Economics 11, 134 - 168.

[26] McCallum, B.T., 1998. Solutions to Linear Rational Expectations Models: A Compact Exposition. Economics Letters 61, 143 - 147. 
[27] Marcet, A., Sargent, T.J., 1989a. Convergence of Least Squares Learning Mechanisms in Self-Referential Linear Stochastic Models. Journal of Economic Theory 48, 337 368.

[28] Marcet, A., Sargent, T.J., 1989b. Least Squares Learning and the Dynamics of Hyperinflation. In: Barnett, W., Geweke, J. and Shell, K. (Eds.), Economic Complexity: Chaos, Sunspots, Bubbles, and Non-linearity, Cambridge University Press, Cambridge, pp. $119-137$.

[29] McKibbin, W.J., 1998. The Economic Crisis in Asia: An Empirical Assessment. Brookings Discussion Paper in International Economics No. 136, The Brookings Institution, Washington D.C.

[30] McKibbin, W.J., 1987. Numerical Solution of Rational Expectations Models With and Without Strategic Behaviour. Reserve Bank of Australia, Research Discussion Paper 8706, August.

[31] McKibbin, W.J., Sachs, J.D., 1991. Global Linkages: Macroeconomic Interdependence and Cooperation in the World Economy, The Brookings Institution, Washington D.C.

[32] McKibbin, W.J., Vines, D., 2003. Changes in Equity Risk Perceptions: Global Consequences and Policy Responses. Mimeo, Australian National University and University of Oxford.

[33] McKibbin, W.J., Vines, D., 2000. Modelling Reality: The Need for Both Intertemporal Optimisation and Stickiness in Models for Policy-making. Oxford Review of Economic Policy 16(4), 106 - 137.

[34] McKibbin, W.J., Wilcoxen, P.J., 1999. The Theoretical and Empirical Structure of the G-Cubed model. Economic Modelling 16, 123 - 48.

[35] McKibbin, W.J., Wilcoxen, P.J., 1998. Macroeconomic Volatility in General Equilibrium. Brookings Discussion Paper in International Economics \#140, The Brookings Institution, Washington DC

[36] McKibbin, W.J., Wilcoxen, P.J., 1994. The Global Costs of Policies to Reduce Greenhouse Gas Emissions. Final Report on US Environmental Protection Agency Cooperative Agreement CR818579-01-0, The Brookings Institution, Washington D.C.

[37] Milani, F., 2006. Expectations, Learning and Macroeconomic Persistence. Mimeo, University of California-Irvine.

[38] Obstfeld, M., Rogoff, K., 1996. Foundations of International Macroeconomics, MIT Press, Cambridge, Massachusetts. 
[39] Orphanides, A., Williams, J.C., 2002. Imperfect Knowledge, Inflation Expectations, and Monetary Policy. Finance and Economics Discussion Series 2002-27, The Federal Reserve Board.

[40] Rudebusch, G.D., Walsh, C.E., 1998. US Inflation Targeting: Pro and Con. Federal Reserve Board of San Francisco Economic Letter, No. 98-18, May.

[41] Sargent, T.J., 1993. Bounded Rationality in Macroeconomics, Oxford University Press, Oxford.

[42] Sargent, T.J., 1987. Dynamic Macroeconomic Theory, Harvard University Press, Cambridge, Massachusetts.

[43] Treadway, A., 1969. On Rational Entrepreneurial Behavior and the Demand for Investment. Review of Economic Studies 36(106), 227 - 239.

[44] Uzawa, H., 1969. Time Preference and the Penrose Effect in a Two-class Model of Economic Growth. Journal of Political Economy 77, 628 - 652.

[45] Williams, N., 2003. Adaptive Learning and Business Cycles. Mimeo, Princeton University. 


\begin{tabular}{|c|c|c|c|c|}
\hline Policy/Shock & RE & RLS & $\bar{g}=\mathbf{0 . 0 3}$ & $\bar{g}=\mathbf{0 . 1}$ \\
\hline \multicolumn{5}{|l|}{ Inflation Target } \\
\hline \multicolumn{5}{|l|}{ US } \\
\hline Real GDP & 0.134 & 0.231 & 0.202 & 0.189 \\
\hline Inflation & 0.272 & 0.366 & 0.332 & 0.319 \\
\hline Real Interest Rate & 0.112 & 0.842 & 0.718 & 0.487 \\
\hline Real Exchange Rate & 0.143 & 0.212 & 0.228 & 0.130 \\
\hline \multicolumn{5}{|l|}{ ROW } \\
\hline Real GDP & 0.014 & 0.078 & 0.053 & 0.038 \\
\hline Inflation & 0.018 & 0.083 & 0.046 & 0.035 \\
\hline Real Interest Rate & 0.015 & 0.707 & 0.503 & 0.152 \\
\hline \multicolumn{5}{|l|}{ Demand } \\
\hline \multicolumn{5}{|l|}{ US } \\
\hline Real GDP & 0.051 & 0.137 & 0.110 & 0.104 \\
\hline Inflation & 0.060 & 0.211 & 0.188 & 0.188 \\
\hline Real Interest Rate & 0.083 & 1.007 & 1.030 & 0.750 \\
\hline Real Exchange Rate & 0.117 & 0.139 & 0.339 & 0.185 \\
\hline \multicolumn{5}{|l|}{ ROW } \\
\hline Real GDP & 0.014 & 0.064 & 0.066 & 0.044 \\
\hline Inflation & 0.026 & 0.085 & 0.072 & 0.069 \\
\hline Real Interest Rate & 0.027 & 0.501 & 1.051 & 0.596 \\
\hline \multicolumn{5}{|l|}{ Productivity } \\
\hline \multicolumn{5}{|l|}{ US } \\
\hline Real GDP & 0.053 & 0.047 & 0.065 & 0.044 \\
\hline Inflation & 0.041 & 0.096 & 0.101 & 0.096 \\
\hline Real Interest Rate & 0.023 & 0.396 & 1.132 & 0.410 \\
\hline Real Exchange Rate & 0.050 & 0.108 & 0.348 & 0.104 \\
\hline \multicolumn{5}{|l|}{ ROW } \\
\hline Real GDP & 0.005 & 0.017 & 0.046 & 0.014 \\
\hline Inflation & 0.005 & 0.017 & 0.029 & 0.014 \\
\hline Real Interest Rate & 0.004 & 0.297 & 0.851 & 0.243 \\
\hline \multicolumn{5}{|l|}{ Equity Risk } \\
\hline \multicolumn{5}{|l|}{ US } \\
\hline Real GDP & 0.273 & 0.082 & 0.098 & 0.068 \\
\hline Inflation & 0.055 & 0.110 & 0.110 & 0.106 \\
\hline Real Interest Rate & 0.117 & 0.462 & 1.482 & 0.556 \\
\hline Real Exchange Rate & 0.245 & 0.108 & 0.509 & 0.172 \\
\hline ROW & & & & \\
\hline Real GDP & 0.023 & 0.042 & 0.065 & 0.030 \\
\hline Inflation & 0.025 & 0.052 & 0.055 & 0.044 \\
\hline Real Interest Rate & 0.024 & 0.406 & 1.387 & 0.469 \\
\hline
\end{tabular}

Table 1: Volatilities of variables under various policies and shocks 


\begin{tabular}{|c|c|c|c|}
\hline Policy/Shock & RLS & $\bar{g}=\mathbf{0 . 0 3}$ & $\bar{g}=\mathbf{0 . 1 0}$ \\
\hline \multicolumn{4}{|l|}{ Inflation Target } \\
\hline \multicolumn{4}{|l|}{ US } \\
\hline Real GDP & 0.755 & 0.809 & 0.430 \\
\hline Inflation & 0.023 & 0.015 & 0.008 \\
\hline Real Interest Rate & 0.210 & 2.743 & 4.136 \\
\hline Real Exchange Rate & 0.046 & 0.077 & 0.160 \\
\hline \multicolumn{4}{|l|}{ ROW } \\
\hline Real GDP & 0.000 & 0.008 & 0.004 \\
\hline Inflation & 0.000 & 0.001 & 0.000 \\
\hline Real Interest Rate & 0.033 & 0.034 & 0.005 \\
\hline \multicolumn{4}{|l|}{ Demand } \\
\hline \multicolumn{4}{|l|}{ US } \\
\hline Real GDP & 0.127 & 0.164 & 0.128 \\
\hline Inflation & 0.039 & 0.005 & 0.009 \\
\hline Real Interest Rate & 0.632 & 4.115 & 8.474 \\
\hline Real Exchange Rate & 0.064 & 0.124 & 0.009 \\
\hline \multicolumn{4}{|l|}{ ROW } \\
\hline Real GDP & 0.001 & 0.042 & 0.009 \\
\hline Inflation & 0.002 & 0.018 & 0.008 \\
\hline Real Interest Rate & 0.273 & 6.054 & 5.671 \\
\hline \multicolumn{4}{|l|}{ Productivity } \\
\hline \multicolumn{4}{|l|}{ US } \\
\hline Real GDP & 0.019 & 0.024 & 0.010 \\
\hline Inflation & 0.001 & 0.026 & 0.002 \\
\hline Real Interest Rate & 0.848 & 8.191 & 1.305 \\
\hline Real Exchange Rate & 0.133 & 0.495 & 0.144 \\
\hline \multicolumn{4}{|l|}{ ROW } \\
\hline Real GDP & 0.002 & 0.000 & 0.000 \\
\hline Inflation & 0.000 & 0.000 & 0.000 \\
\hline Real Interest Rate & 0.043 & 0.078 & 0.006 \\
\hline \multicolumn{4}{|l|}{ Equity Risk } \\
\hline \multicolumn{4}{|l|}{ US } \\
\hline Real GDP & 2.192 & 3.358 & 2.404 \\
\hline Inflation & 0.000 & 0.020 & 0.002 \\
\hline Real Interest Rate & 2.030 & 9.819 & 2.552 \\
\hline Real Exchange Rate & 1.174 & 0.197 & 0.993 \\
\hline \multicolumn{4}{|l|}{ ROW } \\
\hline Real GDP & 0.054 & 0.203 & 0.058 \\
\hline Inflation & 0.001 & 0.009 & 0.001 \\
\hline Real Interest Rate & 0.381 & 4.352 & 1.163 \\
\hline
\end{tabular}

Table 2: MSE of variables under various policies and shocks 


\begin{tabular}{|c|c|c|c|c|}
\hline \multirow[b]{2}{*}{ Policy/Shock } & \multicolumn{2}{|c|}{ Year 1} & \multicolumn{2}{|c|}{ Year 5} \\
\hline & RE & $\bar{g}=\mathbf{0 . 1}$ & RE & $\bar{g}=0.1$ \\
\hline \multicolumn{5}{|l|}{ Inflation Target } \\
\hline Real GDP & 1.314 & 1.315 & 0.157 & 0.161 \\
\hline Inflation & 2.785 & 2.736 & 0.195 & 0.059 \\
\hline Real Interest Rate & -1.279 & -0.906 & 0.050 & 1.127 \\
\hline $\begin{array}{l}\text { Real Exchange Rate } \\
\text { ROW }\end{array}$ & 1.668 & 1.106 & -0.042 & -0.174 \\
\hline Real GDP & 0.087 & 0.191 & -0.060 & -0.076 \\
\hline Inflation & -0.153 & 0.190 & -0.004 & -0.123 \\
\hline Real Interest Rate & -0.158 & 0.288 & 0.041 & 0.306 \\
\hline \multicolumn{5}{|l|}{ Demand } \\
\hline US & & & & \\
\hline Real GDP & 0.278 & 1.078 & -0.229 & -0.179 \\
\hline Inflation & 0.668 & 1.791 & -0.086 & -0.264 \\
\hline Real Interest Rate & 0.825 & 6.751 & 0.006 & -0.907 \\
\hline $\begin{array}{l}\text { Real Exchange Rate } \\
\text { ROW }\end{array}$ & -1.179 & -0.424 & -0.016 & -0.089 \\
\hline Real GDP & -0.032 & 0.285 & -0.014 & -0.051 \\
\hline Inflation & 0.269 & 0.569 & -0.033 & -0.027 \\
\hline Real Interest Rate & 0.269 & 2.060 & -0.026 & -0.375 \\
\hline \multicolumn{5}{|l|}{ Productivity } \\
\hline US & & & & \\
\hline Real GDP & 0.427 & 0.053 & 0.109 & 0.079 \\
\hline Inflation & -0.452 & -0.934 & 0.059 & 0.093 \\
\hline Real Interest Rate & -0.152 & -3.115 & -0.014 & 0.302 \\
\hline Real Exchange Rate & 0.466 & 0.033 & 0.033 & 0.016 \\
\hline ROW & & & & \\
\hline Real GDP & 0.025 & -0.056 & -0.007 & 0.004 \\
\hline Inflation & -0.043 & -0.102 & 0.009 & -0.008 \\
\hline Real Interest Rate & -0.025 & -0.294 & 0.010 & 0.069 \\
\hline \multicolumn{5}{|l|}{ Equity Risk } \\
\hline US & & & & \\
\hline Real GDP & -0.393 & -0.707 & -1.187 & -0.132 \\
\hline Inflation & -0.199 & -0.985 & 0.202 & 0.033 \\
\hline Real Interest Rate & -0.585 & -3.320 & -0.196 & 0.197 \\
\hline $\begin{array}{l}\text { Real Exchange Rate } \\
\text { ROW }\end{array}$ & 1.562 & -0.323 & -0.624 & -0.047 \\
\hline Real GDP & 0.077 & -0.288 & 0.048 & -0.016 \\
\hline Inflation & -0.252 & -0.427 & 0.072 & 0.010 \\
\hline Real Interest Rate & -0.120 & -1.136 & -0.011 & 0.006 \\
\hline
\end{tabular}

Table 3: Transmission of policies and shocks 


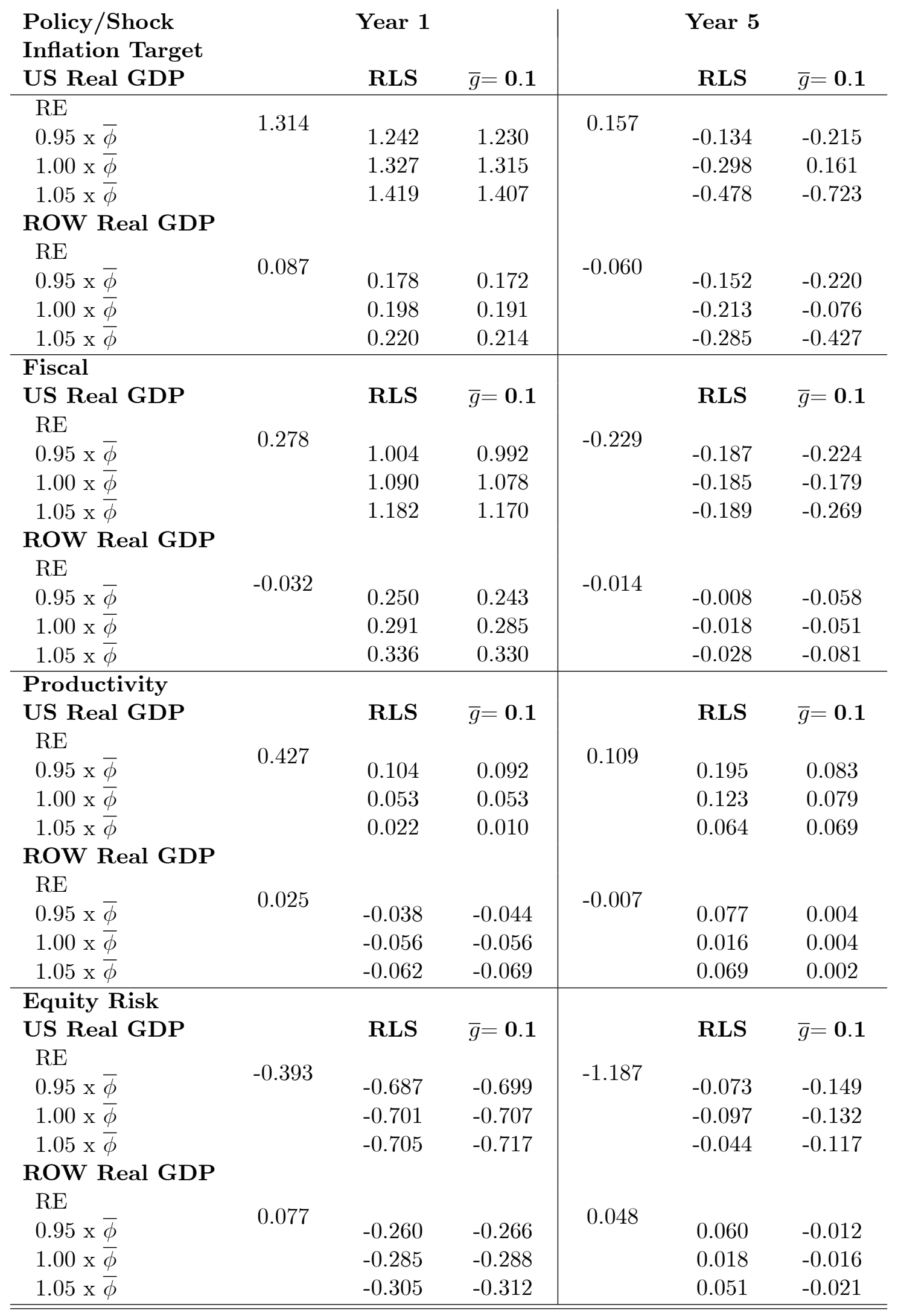

Table 4: Effects on initial values on international transmission of shocks 

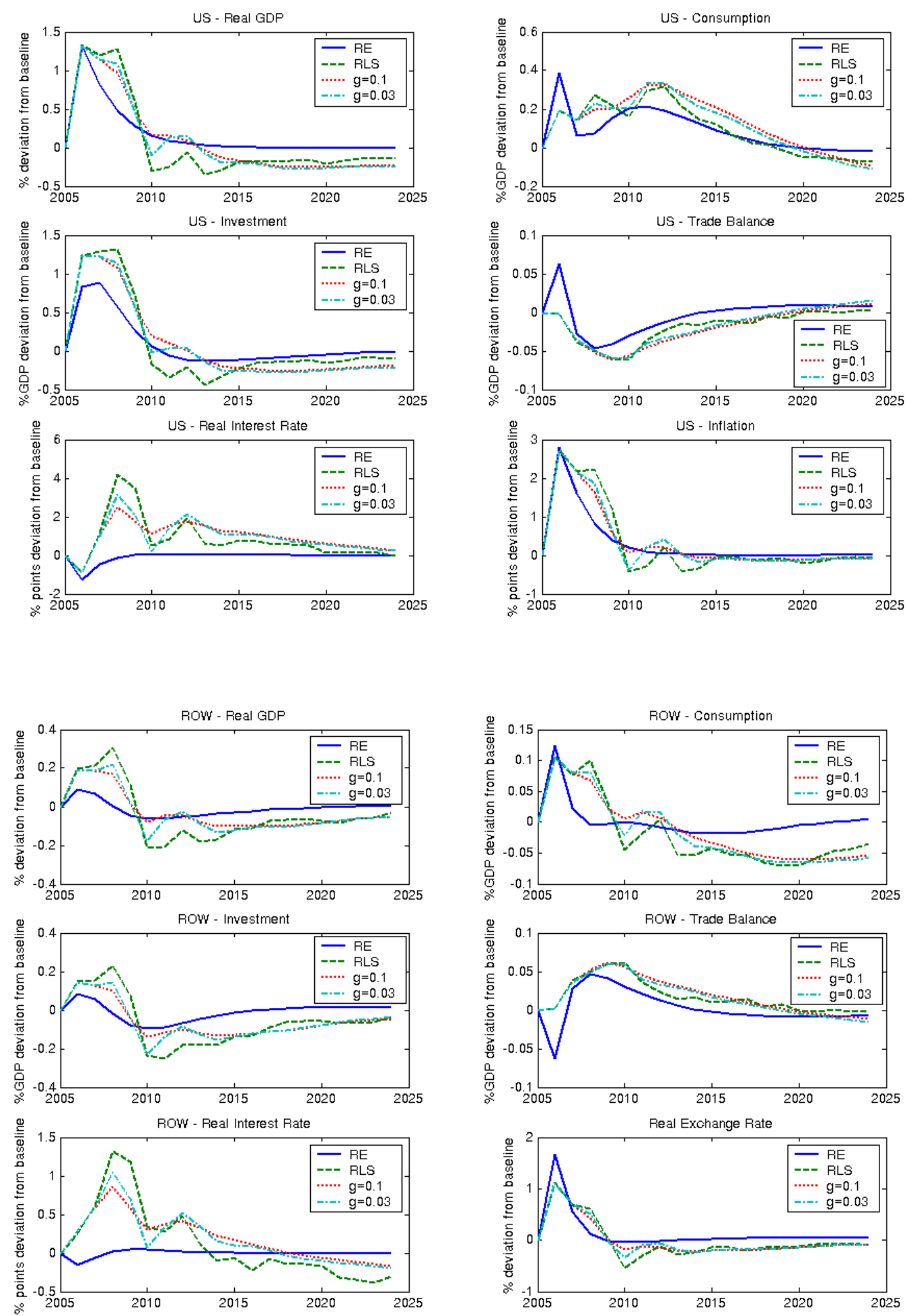

Figure 1: RE versus learning responses to inflation target shock 

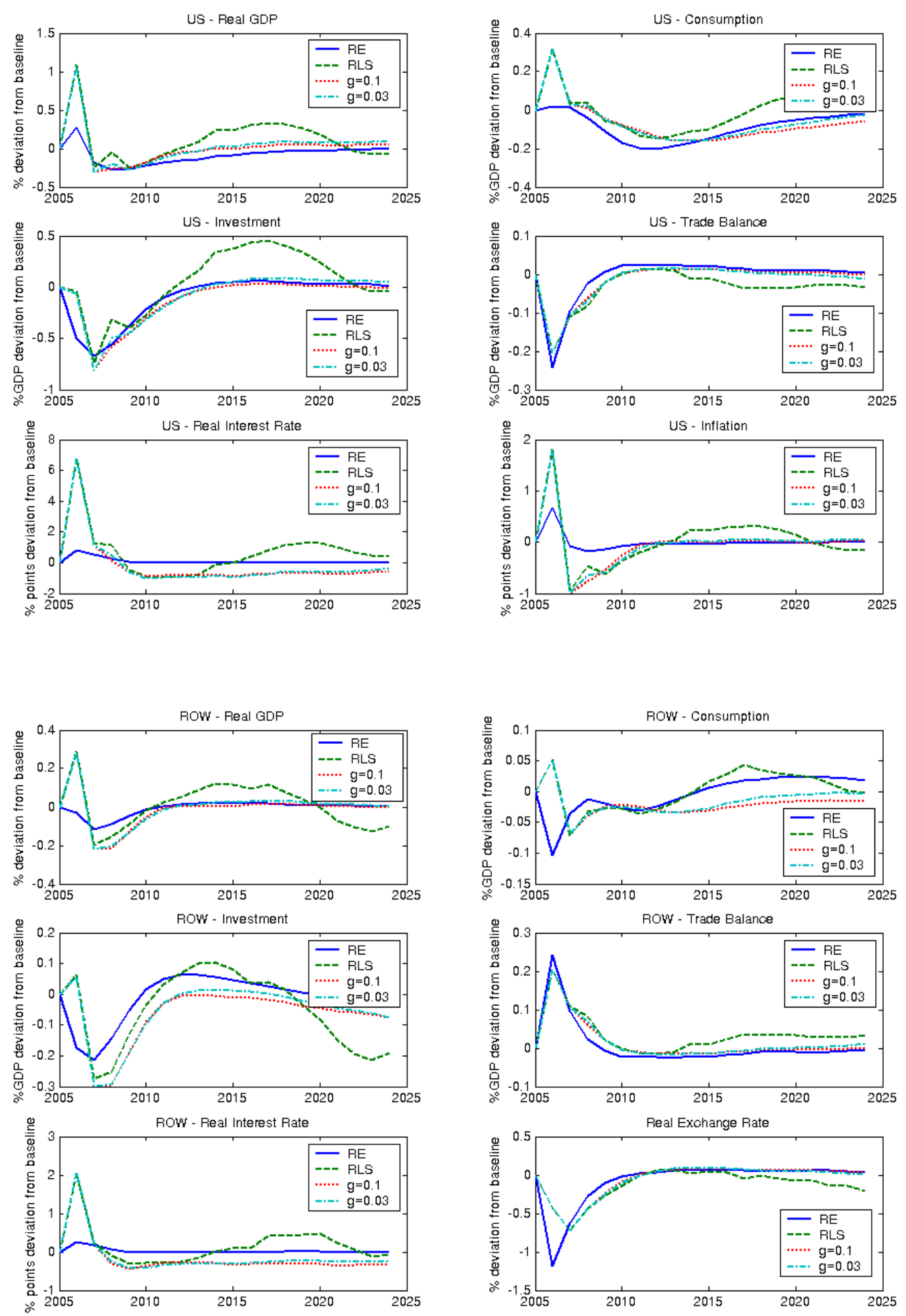

Figure 2: RE versus learning responses to fiscal shock 

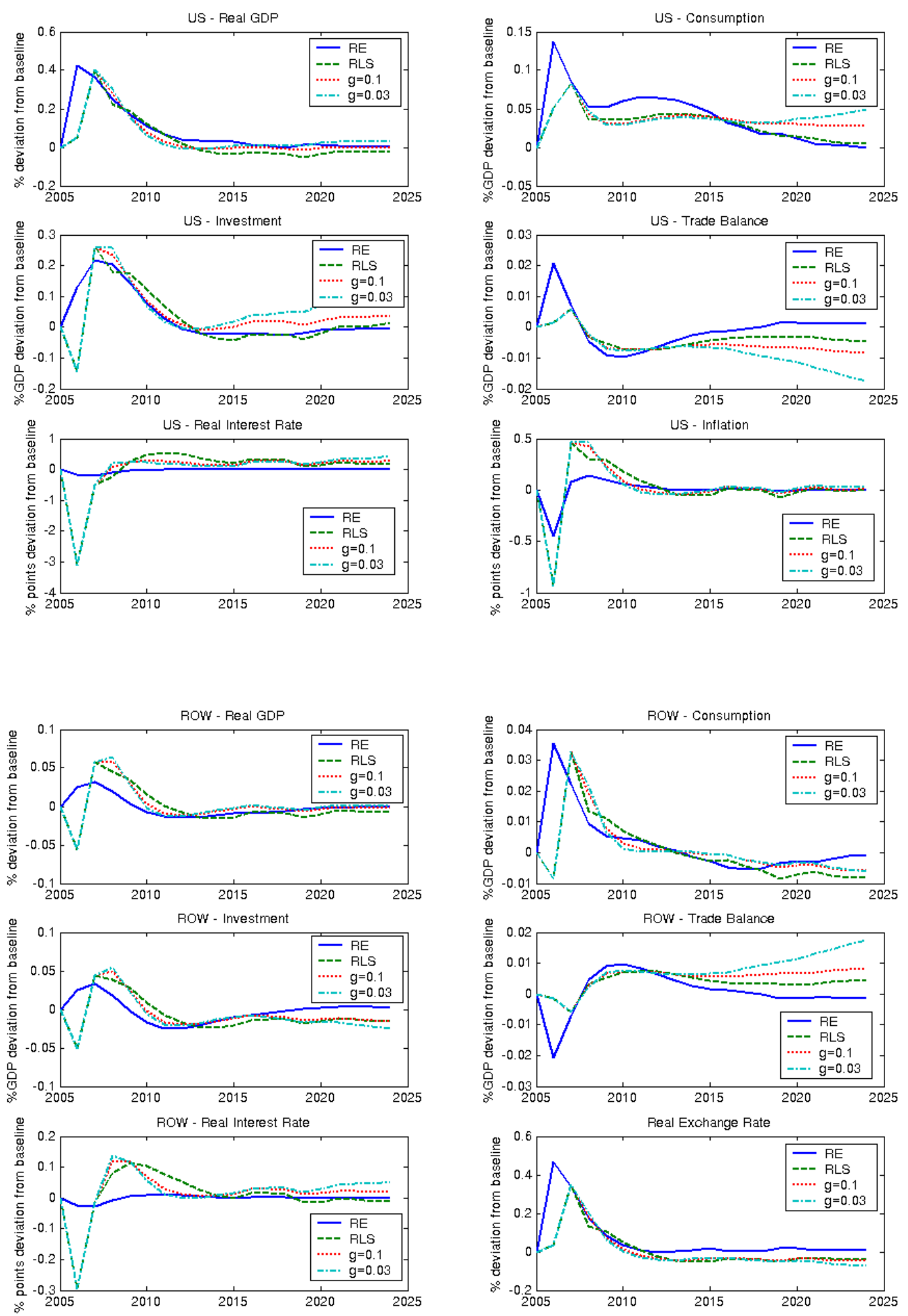

Figure 3: RE versus learning responses to productivity shock 

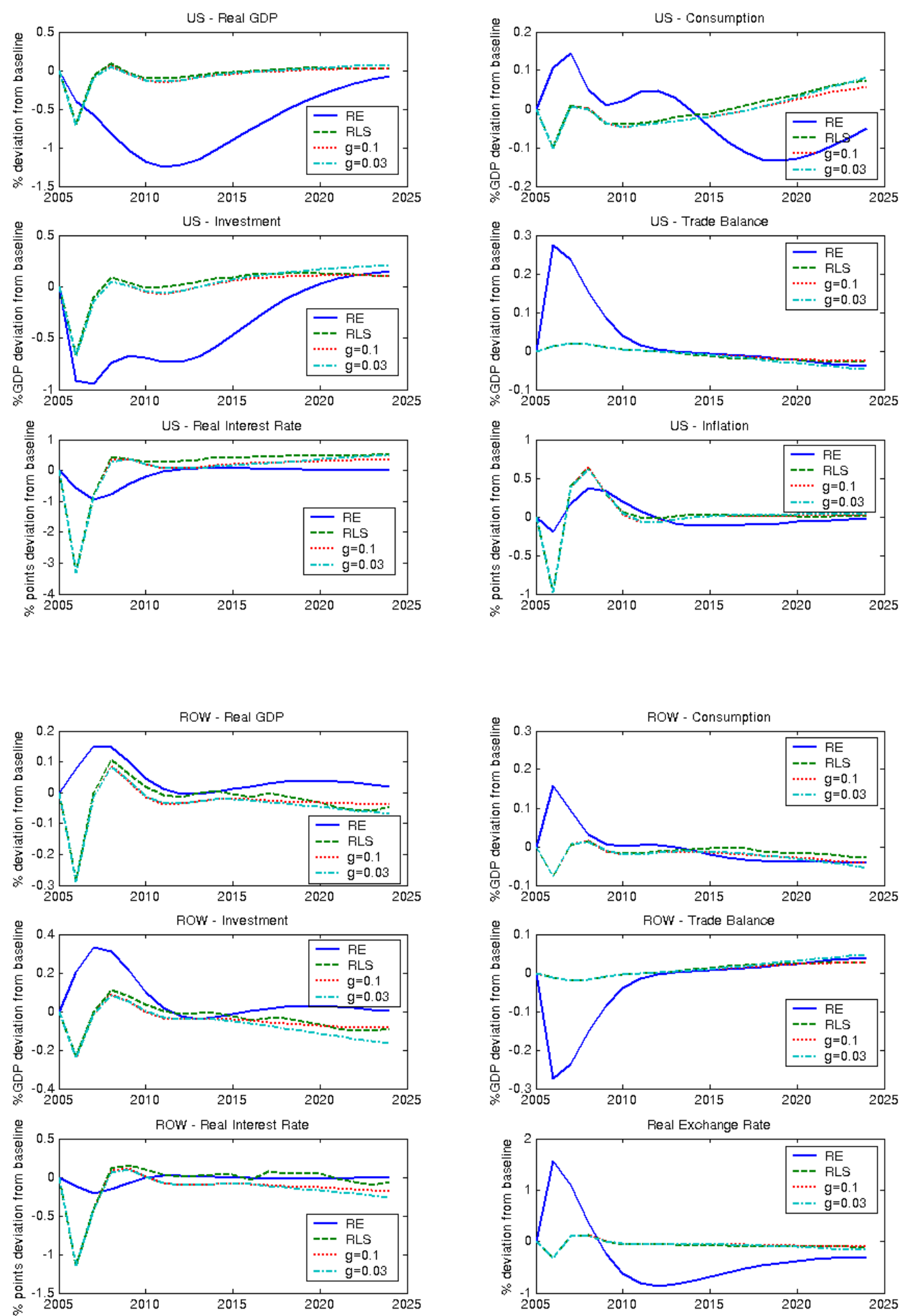

Figure 4: RE versus learning responses to equity risk shock 

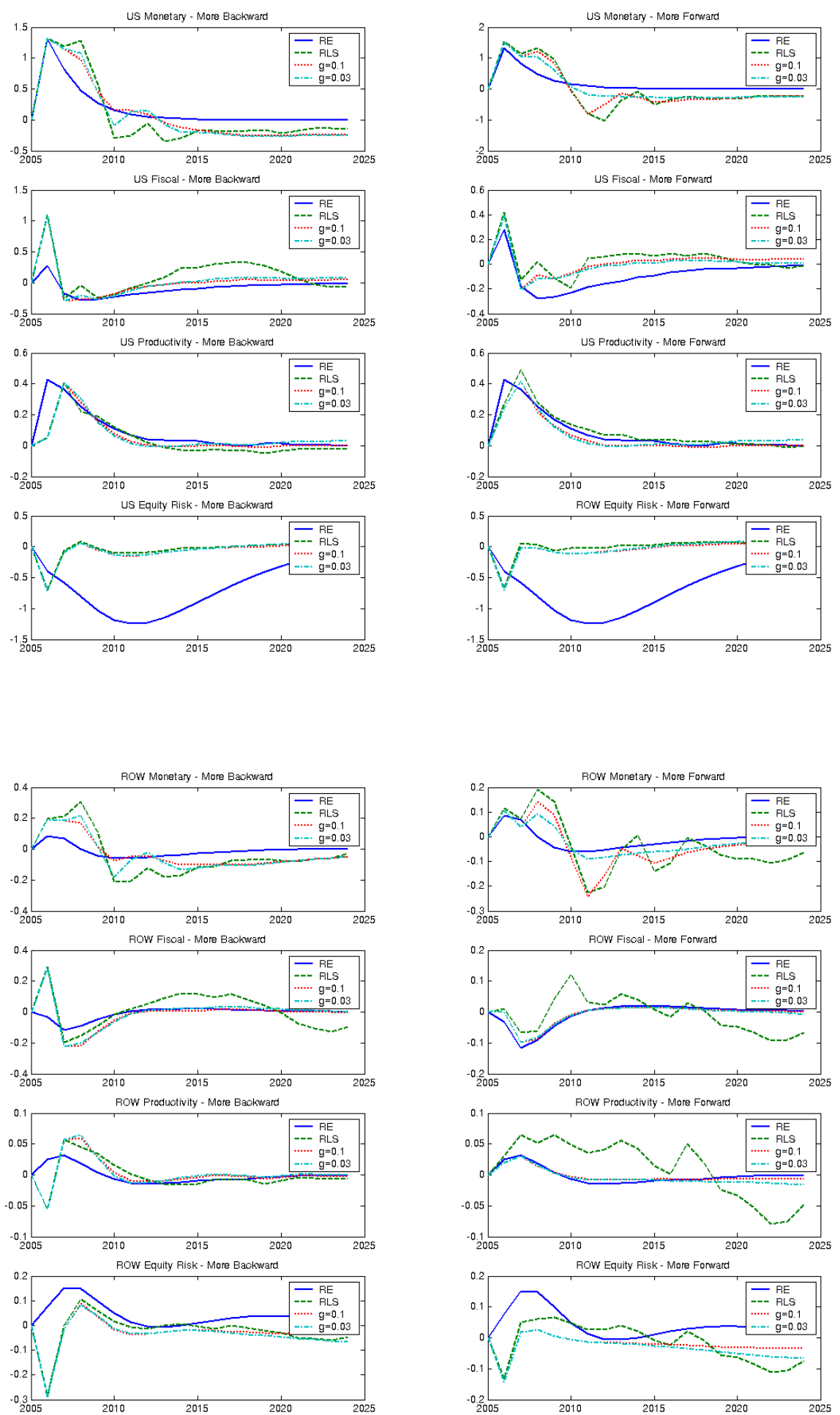

Figure 5: Effects of varying degree of forward- and backward-looking behaviors 

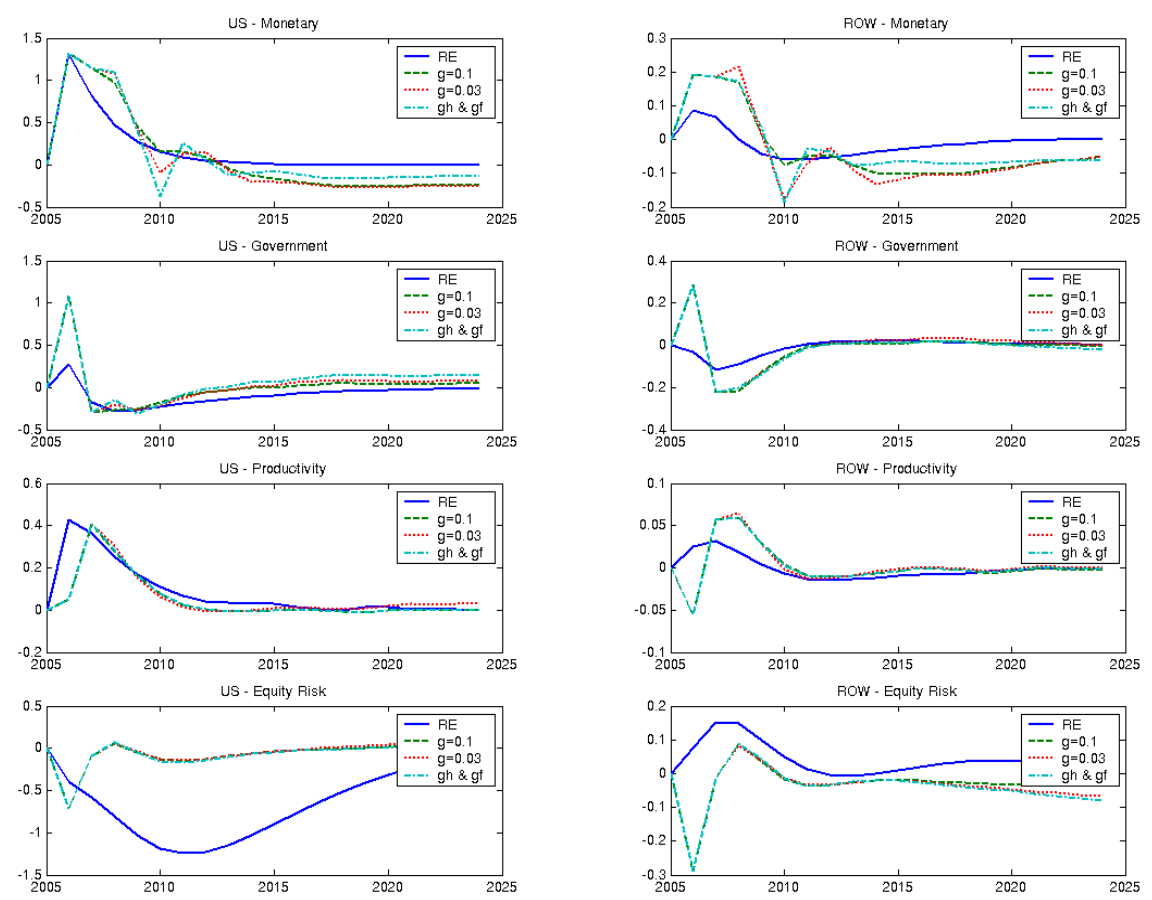

Figure 6: Effects of different constant gains across countries 